\title{
SECCIÓN LULIANA
}





\title{
La lengua de la versión latina del Liber de doctrina puerili de Ramon Llull
}

\author{
Jaume Medina \\ Universitat Autònoma de Barcelona \\ jaume.medina@uab.cat \\ Recibido: abril de 2011. Acepatado: mayo de 2011
}

\begin{abstract}
Resumen: Una comparación del léxico y de la sintaxis usados en las tres versiones del Liber de doctrina puerili de Ramon Llull, transmitidas por la tradición manuscrita.
\end{abstract}

Palabras clave: lexicografía latina medieval, sintaxis latina medieval, tradición manuscrita, filología latina, Ramon Llull.

Résumé: Une comparaison du vocabulaire et de la syntaxe utilisés dans les trois versions du Liber puerilidoctrine de Ramon Llull, transmises par la tradition manuscrite.

Mots-clés: lexicographie latine médiévale, syntaxe latine médiévale, tradition manuscrite, philologielatine, Ramon Llull.

Como es sabido, Ramon Llull (Palma de Mallorca? 1232/33-Palma de Mallorca 1315/16) escribió la mayor parte de sus obras en catalán, aunque la mayor parte de ellas se nos han conservado sólo en su traducción latina. Por lo que respecta al Liber de doctrina puerili (1274-1276), uno de los primeros escritos del maestro, la obra se ha conservado en su lengua original y en latín. Sin embargo, la traducción latina ha llegado hasta nosotros en tres versiones distintas.

El texto latino del Liber de doctrina puerili nos ha sido trasmitido por cuatro manuscritos, de los que dos, $M N$, pertenecen al s. XIV (primer tercio y segunda mitad, respectivamente),${ }^{1}$ uno, $L,{ }^{2}$ al s. XV, ${ }^{3}$ y otro, $P,{ }^{4}$ al s. XVIII. Sin

${ }^{1}$ N München, Bayerische Staatsbibliothek, Clm. 10549 (Primer tercio del s. XIV); M MünCHEN, Bayerische Staatsbibliothek, Clm. 10548 (Segunda mitad del s. XIV).

${ }^{2}$ L LyON, Bibliothèque Publique, Fonds Général 258 (XV).

3 Sin embargo, la traducción latina del Liber de doctrina puerili contenida en este manuscrito es de principios del siglo XIV, ya que en el colofón está fechada en el año 1313.

${ }^{4}$ P Palma, Biblioteca Pública, 1072 (XVIII). 
embargo, a semejanza de lo que ocurre con otras obras lulianas, estos cuatro manuscritos ofrecen hasta tres versiones latinas diferentes: una ha sido transmitida por $M N$, otra por $L$ y otra por $P$.

Por lo que se refiere a $M N$ hay que decir, por una parte, que, aunque presenten una misma versión, en unas pocas ocasiones (especialmente en los capítulos XV-XVII) difieren profundamente en la lectura (en el resto de la obra, exceptuadas algunas variantes ocasionales, coinciden plenamente), y, por otra, que, al haber perdido $N$ algunos folios, el texto contenido en estos ha podido ser leído en su integridad solamente a través de $M$.

Por su parte, $L$ y $P$ presentan sus propias versiones. Estas son muy próximas entre ellas y a la vez muy diferentes de la ofrecida por $M N$, aunque hay que tener presente que $P$ con mucha frecuencia se acerca a la manera de redactar de $M N$. Pero a pesar de que en general las versiones transmitidas por $L$ y $P$ coinciden en la distribución de los capítulos y de los párrafos, así como en la manera de transmitir el contenido, sin embargo presentan una respecto a otra una enorme cantidad de variantes en lo que se refiere al léxico, a la sintaxis e incluso al mismo contenido de algunos de los párrafos, lo que imposibilita su organización en un solo texto. Probablemente, pues, $L$ y $P$ toman el punto de arranque en una misma versión. Sin embargo, $L$ incorpora un capítulo (De militibus, situado entre los capítulos LXXX y LXXXI de las otras dos versiones) que no se encuentra en ningún otro códice latino, ni tampoco en ninguno de los que transmiten el texto catalán, lo que singulariza a este códice dentro del conjunto de la tradición manuscrita.

En cuanto a los títulos de los grandes apartados en que se divide la obra, solamente $P$ da con regularidad la numeración de las diversas partes (prima ... decima pars). A su vez, $P$ se distingue de $M N L$ en el hecho de que, en el prólogo, 3 , y en el título del cap. I, $P$ habla de los doce artículos de la fe católica, mientras que MNL hablan de catorce artículos. Y asimismo, en el cap. LXXVII, mientras que $M N L$ hablan de cinco principios de la naturaleza, $P$ habla de cuatro. Igualmente, en la segunda parte, $M N$ hablan De decem mandatis, mientras que $L P$ hablan De decem praeceptis. En la sexta parte, $M N$ hablan De septem gaudiis dominae nostrae, mientras que LP dicen: De septem gaudiis nostrae dominae sanctae Mariae. En la séptima parte, $M N$ hablan De septem uirtutibus, quae sunt uiae salutis, mientras que $L P$ dicen: De septem uirtutibus, quae sunt uiae saluationis. En la octava parte, $M N L$ hablan De septem peccatis mortalibus, mientras que $P$ prolonga ampliamente esta entrada: De septem mortalibus peccatis, per quae homo uadit ad perdurabilem damnationem. En cambio, el título de la novena parte es el mismo en las tres versiones. En la décima parte, $M N L$ coinciden al hablar De septem artibus, mientras que $P$ habla De septem artibus et quattuor scientiis et artibus mechanicis. En el capítulo LXXIII, $L$ introduce unas rúbricas De logica, de rhetorica, y en el LXXIIII unas rúbricas De arithmetica, De musica, De astronomia. Por su parte, antes de comenzar el capítulo LXXX, $M N$ presentan un título que no se encuentra en $L P$ y que se refiere a los temas que se van a tratar hasta el final del libro, es decir, De materiis diuersis. Finalmente, en el capítulo XCVII, dos manuscritos $(N P)$ hablan de las siete edades del mundo y los dos restantes $(M L)$ de las ocho edades; de hecho la ex- 
plicación de esta dualidad se encuentra en el párrafo 13, donde se dice que «octaua aetas est post finem mundi».

Por otra parte, son muchos los párrafos que se encuentran en $L P$ y que $M N$ omiten (por ejemplo, LXI, 7; LXIII, 5, 7; LXV, 4; LXVI, 4, 5).

Al comparar entre $L$ y $P$, se puede observar que sólo $P$ transmite el texto íntegro, mientras que $L$ ofrece respecto a $P$ diversas lagunas breves y dos extensas (capítulos XXIII, 6-8 y XXVII, 4-5). Por otra parte, $P$, carente de lagunas y de errores, escrito con nitidez y sostenida firmeza desde el principio hasta el fin, es el manuscrito que, a pesar de las reducidas dimensiones de su letra, mejor se puede leer.

A su vez, $L$, además de la omisión de algunos pasajes existentes en $P$ (capítulos XXIII, 6-8 y XXVI, 4-5), está lleno de vacilaciones: unas debidas probablemente al mismo copista, que en algunas ocasiones tachó el texto y a continuación escribió sus propias correcciones; otras debidas a una segunda mano, que añadió (sobre las mismas líneas del texto — con una letra a menudo difícil de leer o interpretar- o al margen - y en este caso se trata, seguramente de una tercera mano-) palabras o expresiones, a veces poniéndolas sobre la palabra corregida, sin tomarse casi nunca la molestia de indicar la necesidad de su supresión (de manera que quedan dos posibilidades de lectura de una misma palabra; por ejemplo «Amabilis / Dilecte», capítulo VII, 8; en este caso, la segunda mano a veces puntea la primera de las dos palabras - indicando así la necesidad de prescindir de ésta-; pero muchas veces se olvida de escribir los puntos, y, por lo tanto, quedan como válidas las dos lecciones).

Así, al contrastar los textos ofrecidos por $L$ y por $P$, el lector puede darse cuenta de que, a pesar de tratarse de dos versiones muy próximas y que parecen haber tenido un origen común, la manera como se concretan tanto en el plano del léxico como en el de la sintaxis hace de ellas dos versiones diferentes e independientes.

Seguidamente vamos a considerar los principales factores de variación lingüística en lo que respecta a los aspectos léxicos y sintácticos a lo largo de las tres versiones latinas del Liber de doctrina puerili, que pueden ser resumidos de la siguiente manera:

\section{A. LAS PALABRAS}

\section{1. clasicizante / popular (y viceversa)}

En general, las tres versiones siguen un mismo modelo de lengua. Sin embargo, a veces presentan, indistintamente, algunos rasgos que las caracterizan como más clasicizantes o como más populares. Así, en el ejemplo siguiente, se diria que la versión ofrecida por $M N$ es más «clásica» (la palabra «uoraginem» le da un cierto aire poético). 
$M N$

IX. De descensu ad inferos

[1] In tempore prophetarum et sanctorum hominum et sanctorum patrum, antequam foret Dei Filius incarnatus ac etiam crucifixus, omnes prophetae et omnes sancti ratione originalis peccati ad inferni uoraginem descendebant. Et quando Dei Filio placuit, ut incarnaretur et nasceretur, beatus Iohannes Baptista fuit nuntius Filii Dei sanctis, qui erant in inferni tenebris cruciati, et denuntiauit illis aduentum Filii Dei, de quo amici Dei gaudium et solacium habuerunt.

$L$

Quando descendit ad inferos. Nonum capitulum

[1] Tempore prophetarum, sanctorum hominum et sanctorum patrum, antequam Filius Dei esset incarnatus et crucifixus, omnes prophetae et sancti, qui credebant in aduentu Filii Dei, ibant ad inferos ratione originalis peccati. Et quando placuit Filio Dei, quod ipse esset incarnatus et natus, sanctus Iohannes Baptista fuit nuntius Filii Dei sanctis, qui erant in poenis infernalibus cruciati, et denuntiauit illis aduentum Filii Dei, de quo fuerunt sancti laeti et consolati.

En cambio, en el ejemplo siguiente, a pesar de que en un principio parezca que la versión de $M N$ es también más clasicizante (ya que presenta la lectura «in quadam camera», más literaria, sin duda que «in una camera», presentada por $L P$ ), sin embargo se puede observar que la introducción temporal de $M N$ («quan$d o »)$ es menos afortunada literariamente que la presentada por $L P$ («dum»):

\begin{tabular}{|c|c|c|}
\hline$X$ & $X$ & $X$ \\
\hline $\begin{array}{l}\text { [4] Item, quando apostoli } \\
\text { stabant inclusi in quadam } \\
\text { camera et ianuae essent } \\
\text { clausae, dominus Iesus } \\
\text { Christus apparuit eis ad os- } \\
\text { tendendum, quod surrexe- } \\
\text { rat corpore glorificato, } \\
\text { quod quidem corpus non } \\
\text { poterat loco seu obiecto } \\
\text { aliquo impediri; et ad os- } \\
\text { tendendum, quod ipse ue- } \\
\text { racius erat homo, escam } \\
\text { petiit et comedit. }\end{array}$ & $\begin{array}{l}\text { [4] Dum apostoli starent } \\
\text { in una camera ianuis clau- } \\
\text { sis, dominus noster Iesus } \\
\text { Christus apparuit eis ad os- } \\
\text { tendendum, quod ipse re- } \\
\text { surrexerat cum corpore } \\
\text { glorificato, quod non habet } \\
\text { impedimentum transeundi } \\
\text { ubique; et ad demonstran- } \\
\text { dum, quod ipse erat uerus } \\
\text { homo, petiit ad comenden- } \\
\text { dum. }\end{array}$ & $\begin{array}{l}\text { [4] Dum apostoli erant in } \\
\text { una camera et portae erant } \\
\text { clausae, noster dominus Ie- } \\
\text { sus Christus apparuit illis } \\
\text { ad demonstrandum, quod } \\
\text { ipse resurrexisset cum glo- } \\
\text { rificato corpore, quod non } \\
\text { habet impedimentum trans- } \\
\text { eundi per omne locum; et } \\
\text { ad demonstrandum, quod } \\
\text { ipse uere esset homo, pe- } \\
\text { tiit, quod manducaret. }\end{array}$ \\
\hline
\end{tabular}




\section{Pronombre / substantivo}

\begin{tabular}{|r|c|c|}
\hline \multicolumn{1}{|c|}{ III } & \multicolumn{1}{|c|}{ III } & III \\
$\begin{aligned} \text { [15] [...] et intellige, qua- } \\
\text { liter } e a, \text { quae comedis, a } \\
\text { diuersis locis dominus tibi } \\
\text { fecit portari. }\end{aligned}$ & $\begin{array}{l}\text { liter } e a, \text { quae comedis, fecit } \\
\text { tibi Deus adduci de diuer- } \\
\text { sis locis. }\end{array}$ & $\begin{array}{l}\text { [15] [...] et intellige, quo- } \\
\text { modo } \text { res, quas manducas, } \\
\text { Deus tibi fecerit adduci de } \\
\text { diuersis locis. }\end{array}$ \\
\hline
\end{tabular}

\section{Tu/Tuus}

\begin{tabular}{|l|l|l|}
\hline III & \multicolumn{1}{|c|}{ III } & III \\
$\begin{array}{c}\text { [16] Deus creauit tibi } \\
\text { oculos }\end{array}$ & $\begin{array}{c}\text { [16] Deus creauit tuos } \\
\text { oculos }\end{array}$ & $\begin{array}{l}\text { [16] Deus creauit tuos } \\
\text { oculos }\end{array}$ \\
\hline
\end{tabular}

\section{Suus / Is / Ipse}

\begin{tabular}{|c|c|c|}
\hline$X$ & $X$ & $X$ \\
\hline $\begin{array}{l}\text { [5] Non est qui posset } \\
\text { enarrare solamen et laeti- } \\
\text { tiam, quam apostoli habue- } \\
\text { runt, quando uiderunt, } \\
\text { quod suus dominus resu- } \\
\text { rrexerat. }\end{array}$ & $\begin{array}{l}\text { [5] Magnam laetitiam, } \\
\text { quam habuerunt apostoli, } \\
\text { qui uiderunt eorum domi- } \\
\text { num resuscitatum, non est, } \\
\text { qui possit narrare. }\end{array}$ & $\begin{array}{l}\text { [5] Non est, qui posset } \\
\text { enarrare magnam laetitiam, } \\
\text { quae fuit inter apostolos, } \\
\text { quando uiderunt ipsorum } \\
\text { dominum resurrexisse. }\end{array}$ \\
\hline
\end{tabular}

\section{Ille / ipse}

\begin{tabular}{|l|l|l|}
\hline \multicolumn{1}{|c|}{ III } & \multicolumn{1}{|c|}{ III } & \multicolumn{1}{c|}{ III } \\
$\begin{array}{c}\text { [16] Deus creauit tibi } \\
\text { oculos, ut cum illis ipsum } \\
\text { uideas in creaturis, quae ip- } \\
\text { sum repraesentant oculis } \\
\text { tuae mentis }\end{array}$ & $\begin{array}{l}\text { [16] Deus creauit tuos } \\
\text { oculos, ut cum ipsis eum in } \\
\text { creaturis, quae ipsum re- } \\
\text { praesentant, uideris oculis } \\
\text { tuae mentis }\end{array}$ & $\begin{array}{l}\text { [16] Deus creauit tuos } \\
\text { oculos, ut cum illis ipsum } \\
\text { uillum reprasenturis, quae } \\
\text { tuae mentis }\end{array}$ \\
\hline
\end{tabular}




\section{Ipse / is / ille}

\begin{tabular}{|r|c|c|}
\hline III & \multicolumn{1}{|c|}{ III } & \multicolumn{1}{c|}{ III } \\
$\begin{array}{r}\text { [16] [...] et Deus creauit } \\
\text { cor tuum, ut sit camera, } \\
\text { qua ipsum teneas et diligas. }\end{array}$ & $\begin{array}{l}{[16][\ldots] \text { et Deus creauit }} \\
\text { tuum cor, ut sit camera, in } \\
\text { qua eum teneas et ames. }\end{array}$ & $\begin{array}{l}\text { [16] [...] et Deus creauit } \\
\text { tum cor, ut sit camera, in } \\
\text { qua illum teneas, et illum } \\
\text { ames. }\end{array}$ \\
\hline
\end{tabular}

\section{Ille / hic / is}

\begin{tabular}{|l|c|c|}
\hline \multicolumn{1}{|c|}{ IIII. De recreatione } & $\begin{array}{c}\text { De recreatione. Quartum } \\
\text { capitulum }\end{array}$ & Cap. 4. De recreatione. \\
$\begin{array}{l}\text { [1] Recreatio est recupe- } \\
\text { rare illud, quod amiserat in } \\
\text { suo populo dominus Deus } \\
\text { noster }\end{array}$ & $\begin{array}{l}\text { [1] Recreatio est recupe- } \\
\text { rare hoc, quod perdiderat } \\
\text { dominus Deus noster in } \\
\text { suo populo }\end{array}$ & $\begin{array}{l}\text { [1] Recreatio est recupe- } \\
\text { rare id, quod noster domi- } \\
\text { nus Deus perdiderat in suo } \\
\text { populo }\end{array}$ \\
\hline
\end{tabular}

\section{Hic / iste}

\begin{tabular}{|c|c|c|}
\hline II & II & II \\
\hline $\begin{array}{l}\text { [8] Non uilipendas, fili } \\
\text { mi, librum istum... }\end{array}$ & $\begin{array}{l}\text { [8] Non despicias, fili, is- } \\
\text { tum librum... }\end{array}$ & $\begin{array}{l}\text { [8] Fili non uilipendas } \\
\text { hunc librum... }\end{array}$ \\
\hline IIII & IIII & IIII \\
\hline $\begin{array}{l}\text { [7] Hic quidem Iesus } \\
\text { Christus uenit in mundum } \\
\text { ad recreandum mundum et } \\
\text { ad humanum genus... }\end{array}$ & $\begin{array}{l}\text { [7] Iste Iesus Christus } \\
\text { uenit in mundum pro recre- } \\
\text { ando ipsum et pro exaltan- } \\
\text { do humanum genus... }\end{array}$ & $\begin{array}{l}\text { [7] Iste Iesus Christus ue- } \\
\text { nit in mundum ad recrean- } \\
\text { dum mundum et ad exal- } \\
\text { tandum humanum genus... }\end{array}$ \\
\hline
\end{tabular}

\section{Is / suus}

\begin{tabular}{|c|c|c|}
\hline III & III & III \\
\hline $\begin{array}{l}{[16][\ldots] \text { creauitque pe- }} \\
\text { des tuos, ut per eius semi- } \\
\text { tas gradiaris }\end{array}$ & $\begin{array}{l}{[16][\ldots] \text { et creauit pedes }} \\
\text { tuos, ut per suas uias uadas }\end{array}$ & $\begin{array}{l}{[16][\ldots] \text { et tuos pedes, ut }} \\
\text { uadas per suas uias }\end{array}$ \\
\hline
\end{tabular}




\begin{tabular}{|c|c|c|}
\hline \multicolumn{1}{|c|}{ VIII } & VIII & VIII \\
$\begin{array}{c}\text { [8] [...] et eius sanguis } \\
\text { per omnia organa sui cor- } \\
\text { poris discurrebat. }\end{array}$ & $\begin{array}{l}\text { [8] [...] et suus praetio- } \\
\text { totumguis decurrebat per }\end{array}$ & $\begin{array}{l}\text { [8] [...] et sanguis decur- } \\
\text { rebat per totum corpus. }\end{array}$ \\
\hline
\end{tabular}

\section{Omnis / hic / iste}

\begin{tabular}{|r|c|c|}
\hline VI & \multicolumn{1}{|c|}{ VI } & \multicolumn{1}{c|}{ VI } \\
$\begin{array}{r}\text { [8] Fili, obligatus es cre- } \\
\text { dere omnia, quae de con- } \\
\text { ceptione Dei Filii tibi dixi. }\end{array}$ & $\begin{array}{l}\text { [8] Obligatus es, fili, ad } \\
\text { credendum his, quae tibi } \\
\text { dico de conceptione Filii } \\
\text { Dei. }\end{array}$ & $\begin{array}{l}\text { [8] Fili, es obligatus ad } \\
\text { credendum ista, quae dico } \\
\text { de conceptione Filii Dei. }\end{array}$ \\
\hline
\end{tabular}

\section{Pro / propter / per}

\begin{tabular}{|c|c|c|}
\hline IIII & IIII & IIII \\
\hline $\begin{array}{l}\text { [9] Fili, si tam malum est } \\
\text { peccare et esse Deo } \\
\text { inoboediens, quod pro solo } \\
\text { uno peccato in ira Dei su- } \\
\text { mus omnes... }\end{array}$ & $\begin{array}{l}\text { [9] Si igitur ita mala res, } \\
\text { fili, sit peccatum et esse } \\
\text { inoboediens Deo, quod } \\
\text { propter unum peccatum } \\
\text { tantummodo fuimus omnes } \\
\text { in ira Dei... }\end{array}$ & $\begin{array}{l}\text { [9] Fili, si tam mala res } \\
\text { est peccare et esse inoboe- } \\
\text { diens Deo, quod per unum } \\
\text { peccatum tantum omnes } \\
\text { fuimus in ira Dei... }\end{array}$ \\
\hline
\end{tabular}

\section{Ergo / igitur}

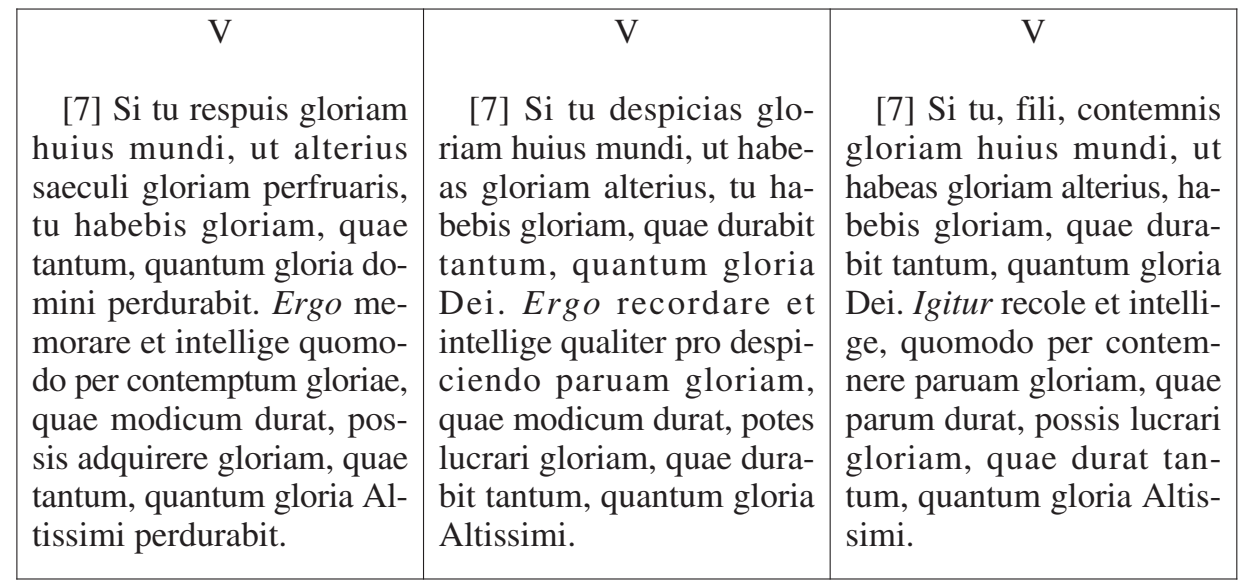




\section{Per hoc / ideo}

\begin{tabular}{|c|c|c|}
\hline VII & VII & VII \\
\hline $\begin{array}{l}\quad[2][\ldots] \text { Ac per hoc, } \\
\text { quando Filio Dei placuit, ut } \\
\text { nasceretur, scias, quod in } \\
\text { loco paupere fuit ortus, ui- } \\
\text { delicet in praesepe ubi ani- } \\
\text { malia comedebant. }\end{array}$ & $\begin{array}{l}\text { [2] [...] Et ideo, quando } \\
\text { placuit Filo Dei, quod nas- } \\
\text { ceretur, natus fuit in pau- } \\
\text { pere loco, uidelicet in prae- } \\
\text { sepio, in quo comedebant } \\
\text { bestiae. }\end{array}$ & $\begin{array}{l}{[2][\ldots] \text { Et ideo cum pla- }} \\
\text { cuit Filio Dei, quod nasce- } \\
\text { retur, fuit natus in paupere } \\
\text { loco, scilicet in praesepio, } \\
\text { ubi comedebant bestiae. }\end{array}$ \\
\hline
\end{tabular}

\section{Ac / et}

\begin{tabular}{|c|c|c|}
\hline VII & VII & VII \\
\hline $\begin{array}{l}\quad[2][\ldots] \text { Ac per hoc, quan- } \\
\text { do Filio Dei placuit, ut nas- } \\
\text { ceretur, scias, quod in loco } \\
\text { paupere fuit ortus, uideli- } \\
\text { cet in praesepe ubi anima- } \\
\text { lia comedebant. }\end{array}$ & $\begin{array}{l}\quad[2][\ldots] \text { Et ideo, quando } \\
\text { placuit Filo Dei, quod nas- } \\
\text { ceretur, natus fuit in pau- } \\
\text { pere loco, uidelicet in prae- } \\
\text { sepio, in quo comedebant } \\
\text { bestiae. }\end{array}$ & $\begin{array}{l}\text { [2] [...] Et ideo cum pla- } \\
\text { cuit Filio Dei, quod nasce- } \\
\text { retur, fuit natus in paupere } \\
\text { loco, scilicet in praesepio, } \\
\text { ubi comedebant bestiae. }\end{array}$ \\
\hline
\end{tabular}

\section{Idcirco / ideo}

\begin{tabular}{|c|c|c|}
\hline $\begin{array}{l}\text { XIII } \\
\text { [7] Oportuit etiam, quod } \\
\text { lex uetus nouam legem } \\
\text { praecederet, sicut funda- } \\
\text { mentum debet esse, ante- } \\
\text { quam fiat domus, et quia } \\
\text { Iudaeos non poenitet cul- } \\
\text { pae mortis, qua Christum } \\
\text { dominum punierunt, nec } \\
\text { credunt uerbis dictis a do- } \\
\text { mino Iesu Christo, nec cre- } \\
\text { dunt illud, quod per anti- } \\
\text { quam legem significabatur, } \\
\text { ideo sunt in statu damna- } \\
\text { tionis, quia ex quo comple- } \\
\text { tum est, quod antiquae le- } \\
\text { gis sacrificia figurabant, } \\
\text { illud non debet amplius ob- } \\
\text { seruari. }\end{array}$ & $\begin{array}{l}\text { XIII } \\
\text { [7] Lex uetus fuit conue- } \\
\text { nienter antequam noua, si- } \\
\text { cut fundamentum oportuit } \\
\text { esse antequam cameram, et } \\
\text { quia Iudaeos non paenitet } \\
\text { culpae, quam habent, eo } \\
\text { quia tractauerunt mortem } \\
\text { domini nostri Iesu Christi, } \\
\text { idcirco sunt in errore et } \\
\text { credunt tenere legem Moy- } \\
\text { si, quam non tenent, eo } \\
\text { quia non sequuntur illud, } \\
\text { quod lex uetus significat de } \\
\text { noua. }\end{array}$ & \begin{tabular}{|l} 
XIII \\
[7] Conuenit, quod uetus \\
lex esset prius quam noua, \\
sicut conuenit, quod funda- \\
menta sint prius quam ca- \\
mera, et quia Iudaeos non \\
paenitet culpae, quam ha- \\
bent, quia tractarunt mor- \\
tem nostri domini Iesu \\
Christi, ideo sunt in errore \\
et putant tenere legem \\
Moysis, quam non tenent, \\
quia non sequuntur hoc, \\
quod uetus lex significat de \\
noua lege.
\end{tabular} \\
\hline
\end{tabular}




\section{Si non / nisi}

\begin{tabular}{|c|c|c|}
\hline IIII & IIII & IIII \\
\hline $\begin{array}{l}\text { [8] Fili, credere te opor- } \\
\text { tet in hunc mundum domi- } \\
\text { num Iesum Christum, de } \\
\text { quo loquor; nam si non } \\
\text { crederes, esses nullatenus } \\
\text { recreatus... }\end{array}$ & $\begin{array}{l}\text { [8] Fili, credere te opor- } \\
\text { tet in ipsum dominum nos- } \\
\text { trum Iesum Christum, de } \\
\text { quo tibi loquor; quia nisi } \\
\text { hoc faceres, non esses re- } \\
\text { creatus... }\end{array}$ & $\begin{array}{l}\text { [8] Fili, conuenit, quod } \\
\text { credas in hunc dominum } \\
\text { Iesum Christum, de quo lo- } \\
\text { quor; nam si hoc non cre- } \\
\text { deres, non esses recreatus... }\end{array}$ \\
\hline
\end{tabular}

\section{Quia / eo quia}

\begin{tabular}{|c|c|c|}
\hline IIII & IIII & IIII \\
\hline $\begin{array}{l}\quad[8][\ldots] \text { in qua existunt } \\
\text { Iudaei et Saraceni et alii in- } \\
\text { fideles, quia non credunt in } \\
\text { aduentum nec in passio- } \\
\text { nem domini nostri Iesu } \\
\text { Christi. }\end{array}$ & $\begin{array}{l}{[8][\ldots] \text { in qua quidem cul- }} \\
\text { pa sunt Iudaei, Saraceni et } \\
\text { ceteri infideles, eo quia } \\
\text { non credunt in aduentu nec } \\
\text { in passione domini Dei } \\
\text { nostri Iesu Christi. }\end{array}$ & $\begin{array}{l}\text { [8] [...] in qua sunt Iuda- } \\
\text { ei et Saraceni et alii infide- } \\
\text { les, quia non credunt in } \\
\text { aduentum nec in passio- } \\
\text { nem nostri domini Dei Iesu } \\
\text { Christi. }\end{array}$ \\
\hline
\end{tabular}

\section{Tam / ita}

\begin{tabular}{|l|c|c|}
\hline \multicolumn{1}{|c|}{ IIII } & \multicolumn{1}{c|}{ IIII } & \multicolumn{1}{c|}{ IIII } \\
$\begin{array}{l}\text { [9] Fili, si tam malum est } \\
\text { peccare et esse Deo } \\
\text { inoboediens... }\end{array}$ & $\begin{array}{l}\text { [9] Si igitur ita mala res, } \\
\text { fili, sit peccatum et esse } \\
\text { inoboediens Deo... }\end{array}$ & $\begin{array}{l}\text { [9] Fili, si tam mala res } \\
\text { est peccare et esseinoboe- } \\
\text { diens Deo... }\end{array}$ \\
\hline
\end{tabular}

\section{Coram / Ante}

\begin{tabular}{|c|c|c|}
\hline VIII & \multicolumn{1}{|c|}{ VIII } & \multicolumn{1}{c|}{ VIII } \\
$\begin{array}{r}{[13][\ldots] \text { si coram se cru- }} \\
\text { ciari uel interfici te uideret. }\end{array}$ & $\begin{array}{l}{[13][\ldots] \text { si quis coram ea }} \\
\text { te interficeret et tormenta- } \\
\text { ret. }\end{array}$ & $\begin{array}{l}{[13][\ldots] \text { si ante illam oc- }} \\
\text { cidereris et cruciareris. }\end{array}$ \\
\hline
\end{tabular}




\section{Comparativo: simple / con plus quam / magis quam}

\begin{tabular}{|r|r|r|}
\hline $\mathrm{V}$ & \multicolumn{1}{|c|}{$\mathrm{V}$} & \multicolumn{1}{c|}{$\mathrm{V}$} \\
$\begin{array}{r}\text { [6] [...] Illud corpus in } \\
\text { die iudicii resurget, ac sole } \\
\text { quidem clarius refulgebit... }\end{array}$ & $\begin{array}{l}\text { suscitabit in die iudicii, et } \\
\text { suit resplendens plus quam } \\
\text { sol... }\end{array}$ & $\begin{array}{l}\text { [6] [...] Istud corpus re- } \\
\text { suscitabitur in die iudicii, } \\
\text { et erit magis resplendens } \\
\text { quam sol }\end{array}$ \\
\hline
\end{tabular}

\section{Comparativo: longe plus / maior / plus}

\begin{tabular}{|c|c|c|}
\hline \multicolumn{1}{|c|}{$\mathrm{V}$} & $\mathrm{V}$ & $\mathrm{V}$ \\
$\begin{array}{c}\text { [6] [...] Illud corpus in } \\
\text { die iudicii resurget, ac sole } \\
\text { quidem clarius refulgebit, } \\
\text { et numquam morietur, et } \\
\text { longe plus gloriae posside- } \\
\text { bit, quam sit tota gloria, } \\
\text { quae consistit in hominibus } \\
\text { huius mundi. }\end{array}$ & $\begin{array}{l}\text { suscitabit illud die iudicii, et } \\
\text { erit resplendens plus quam } \\
\text { sol, et nunquam morietur, } \\
\text { et habebit maiorem glo- } \\
\text { riam, quam sit tota gloria, } \\
\text { quae est in omnibus homi- } \\
\text { nibus huius mundi. }\end{array}$ & $\begin{array}{l}\text { [6] [...] Istud corpus re- } \\
\text { suscitabitur in die iudicii, } \\
\text { et erit magis resplendens } \\
\text { quam sol, et nullo tempore } \\
\text { morietur; et habebit plus } \\
\text { gloriae, quam sit omnis } \\
\text { gloria, quae est in homini- } \\
\text { bus huius mundi. }\end{array}$ \\
\hline
\end{tabular}

\section{Superlativo: multum+adj. / terminación de superlativo}

\begin{tabular}{|c|c|c|}
\hline$X$ & $X$ & $X$ \\
\hline $\begin{array}{l}\text { [3] [...] Nam maior uir- } \\
\text { tus, quam I homo possit ha- } \\
\text { bere, est caritas, ad osten- } \\
\text { dendum, quod Dei Filio sit } \\
\text { caritas multum grata, pri- } \\
\text { mo ipse Dei Filius apparuit } \\
\text { Magdalenae. }\end{array}$ & $\begin{array}{l}\quad[3][\ldots] \text { Et quia caritas est } \\
\text { melior uirtus, quae possit } \\
\text { haberi, ad ostendendum, } \\
\text { quod caritas est Filio Dei } \\
\text { gratissima, Filius Dei ap- } \\
\text { paruit Magdalenae. }\end{array}$ & $\begin{array}{l}{[3][\ldots] \text { Et quia caritas est }} \\
\text { melior uirtus, quam homo } \\
\text { potest habere, ad demons- } \\
\text { trandum, quod caritas sit } \\
\text { multum grata Filio Dei, ap- } \\
\text { paruit Magdalenae. }\end{array}$ \\
\hline
\end{tabular}




\section{Esse / existere}

\begin{tabular}{|c|c|c|}
\hline IIII & IIII & IIII \\
\hline $\begin{array}{l}\text { [8] [...] in qua existunt } \\
\text { Iudaei et Saraceni et alii in- } \\
\text { fideles, quia non credunt in } \\
\text { aduentum nec in passio- } \\
\text { nem domini nostri Iesu } \\
\text { Christi. }\end{array}$ & $\begin{array}{l}\quad[8][\ldots] \text { in qua quidem } \\
\text { culpa sunt Iudaei, Sarace- } \\
\text { ni et ceteri infideles, eo } \\
\text { quia non credunt in aduen- } \\
\text { tu nec in passione domini } \\
\text { Dei nostri Iesu Christi. }\end{array}$ & $\begin{array}{l}\text { [8] [...] in qua sunt It } \\
\text { daei et Saraceni et alii inf } \\
\text { deles, quia non credunt } \\
\text { aduentum nec in passic } \\
\text { nem nostri domini Dei Ies } \\
\text { Christi. }\end{array}$ \\
\hline
\end{tabular}

\section{Esse / stare}

\begin{tabular}{|c|c|c|}
\hline VIII & VIII & VIII \\
[3] [...] eadem nocte Ie- & [3] [...] Iesus Christus & [3] [...] Iesus Christus \\
$\begin{array}{l}\text { sus Christus in oratione } \\
\text { stabat eius apostolis... }\end{array}$ & erat in oratione illa nocte... & illa nocte stabat in oratione \\
\hline
\end{tabular}

\section{Numquam velle / Nolle / Non velle}

\begin{tabular}{|c|c|c|}
\hline VIII & VIII & VIII \\
\hline $\begin{array}{l}\text { [17] Scis tu, quare prop- } \\
\text { ter Iesum Christum mori } \\
\text { non uis? Quia mori ni- } \\
\text { mium pertimescis, et quia } \\
\text { plus in hoc mundo, quam } \\
\text { in alio esse desideras. } \\
\text { Vnde, si tu fuisses Chris- } \\
\text { tus, numquam mori uoluis- } \\
\text { ses, nec mortuus unquam } \\
\text { esset, quia, si uoluisset, } \\
\text { numquam Dei Filius fuis- } \\
\text { set mortem passus. }\end{array}$ & $\begin{array}{l}\text { [17] Scis tu quare non } \\
\text { uis mori amore Iesu Chris- } \\
\text { ti? Eo quia mors infert tibi } \\
\text { timorem, et ideo quia plus } \\
\text { diligis esse in hoc mundo, } \\
\text { quam in alio. Ergo, si tu } \\
\text { fuisses Iesus Christus, iam } \\
\text { nolles mori nec mortuus } \\
\text { fuisses, cum ita sit, quod } \\
\text { Iesus Christus non mortuus } \\
\text { fuisset, si uoluisset. }\end{array}$ & $\begin{array}{l}\text { [17] Scisne quare non uis } \\
\text { mori propter Iesum Chris- } \\
\text { tum? Quia mors tibi facit } \\
\text { timorem, et quia magis } \\
\text { amas esse in hoc mundo, } \\
\text { quam in alio. Vnde, si tu } \\
\text { fuisses Iesus Christus, non } \\
\text { uoluisses mori, nec fuisses } \\
\text { mortuus, cum Iesus Chris- } \\
\text { tus non fuisset mortuus, si } \\
\text { uoluisset non mori. }\end{array}$ \\
\hline
\end{tabular}




\section{B. SINTAXIS}

\section{Construcción inversa}

I
[7] Deus est amandus,
quia totus bonus est; Deus
est magnus, quia in eo om-
nia terminantur; Deus est
durabilis, quoniam non ha-
bet principium neque fi-
nem; timendus est Deus,
quoniam in eo fortitudo
est, et omnia scit, praeteri-
ta, praesentia et futura.
II
[1] Obligatus es, dilecte
fili, credere in sanctam tri-
nitatem domini Dei nostri,
quae trinitas unus est
Deus...

[7] Quod non sufficis intelligere non abneges...

[7] Scis, qua de causa ita I subtiliter tibi loquor?

[8] Non uilipendas, fili mi, librum istum, quia id, quod in eo est, grosso modo traditur; quoniam factus non est exaltato intellectui, sed ut intellectus puerilis ad intelligendum istum mundum ualeat exaltari.

\section{De creatione}

[1] Creator est Deus, qui de nihilo fecit mundum.
[7] Amabilis est Deus, quia totus bonus est; magnus est Deus, quia omne, quod est, terminatur in eo; durabilis est Deus, quia caret principio et fine; timibilis est Deus, quia omne posse est in ipso, et omnia scit.

\section{II}

[1] Obligatus es, dilecte fili, ad credendum in sancta trinitate domini Dei nostri, quae quidem trinitas est unus Deus...

[7] Non discredas omne illud, quod non potes intelligere...

[7] Et scis tu, quare sic loquor ita subtiliter?

[8] Non despicias, fili, istum librum, eo quia grosso modo narratur; quia non est factus ad exaltandum intellectum, immo est factus, ut intellectus puerorum possit esse exaltatus ad intelligendum istum mundum et Deum.

Tertium capitulum. De creatione

[1] Creator est factor, qui fecit mundum de nihilo.
I

[7] Deus est amabilis, quia est totus bonus; Deus est magnus, quia omnia, quae sunt, terminantur in illo; Deus est durabilis, quia non habet principium nec finem; Deus est timibilis, quia in illo est omnis potestas et scit omnia.

II

[1] Obligatus es, amabilis fili, ad credendum in sanctam trinitatem nostri domini Dei, quae trinitas est unus Deus...

[7] Non discredas omne illud, quod non potes intelligere...

[7] Et scis, quare tibi tam subtiliter loquor?

[8] Fili non uilipendas hunc librum, quia grosso modo enarratur; quia non est factus exaltato intellectui, sed est factus, ut intellectus infantium possint exaltari ad intelligendum hunc mundum et Deum.

Cap. 3. De creatura

[1] Creator est factor, qui de nihilo fecit mundum. 


\begin{tabular}{|c|c|c|}
\hline $\mathrm{X}$ & $X$ & $X$ \\
\hline $\begin{array}{l}\text { [5] Non est qui posset } \\
\text { enarrare solamen et laelti- } \\
\text { tiam, quam apostoli habue- } \\
\text { runt, quando uiderunt, } \\
\text { quod suus dominus resur- } \\
\text { rexerat. }\end{array}$ & $\begin{array}{l}\text { [5] Magnam laetitiam, } \\
\text { quam habuerunt apostoli, } \\
\text { qui uiderunt eorum domi- } \\
\text { num resuscitatum, non est, } \\
\text { qui possit narrare. }\end{array}$ & $\begin{array}{l}\text { [5] Non est, qui posset } \\
\text { enarrare magnam laeti- } \\
\text { tiam, quae fuit inter apos- } \\
\text { tolos, quando uiderunt ip- } \\
\text { sorum dominum } \\
\text { resurrexisse. }\end{array}$ \\
\hline
\end{tabular}

\section{Omissión de algunas palabras}

\begin{tabular}{|c|c|c|}
\hline II & II & II \\
\hline $\begin{array}{l}\text { [7] Quod non sufficis } \\
\text { intelligere non abneges; } \\
\text { quia si ea abnegas, tu af- } \\
\text { fectas tuum intellectum } \\
\text { esse maiorem quam sint ea, } \\
\text { quae tuus de Deo nequit } \\
\text { apprehendere intellectus. }\end{array}$ & $\begin{array}{l}\text { [7] Non discredas omne } \\
\text { illud, quod non potes intel- } \\
\text { ligere; quia si facias I tu uis } \\
\text { facere maiorem tuum inte- } \\
\text { llectum, quam sunt omnia. }\end{array}$ & $\begin{array}{l}\text { [7] Non discredas omne } \\
\text { illud, quod non potes intel- } \\
\text { ligere; quia si hoc facis, tu } \\
\text { uis tuum intellectum maio- } \\
\text { rem facere, quam omnia. }\end{array}$ \\
\hline
\end{tabular}

\section{Expresión más breve / Expresión más desarollada (y viceversa)}

\begin{tabular}{|c|c|c|}
\hline VI & VI & VI \\
\hline $\begin{array}{l}\text { [6] In illa quidem sapien- } \\
\text { tia et in illa uirtute ac in illa } \\
\text { potestate, in qua Iesus } \\
\text { Christus fuit, quando adul- } \\
\text { tus extitit ac aetatis perfec- } \\
\text { tae, habuit complementum. }\end{array}$ & $\begin{array}{l}\text { [6] In illa sapientia et in } \\
\text { illa uirtute et in illo posse, } \\
\text { in quibus fuit Iesus Chris- } \\
\text { tus, quando creuit et habuit } \\
\text { perfectam aetatem, in illa } \\
\text { eadem sapientia et cum illo } \\
\text { posse et uirtute fuit inconti- } \\
\text { nenti, quod fuit coniunctus } \\
\text { cum Filio Dei. }\end{array}$ & $\begin{array}{l}\text { [6] In illa sapientia et in } \\
\text { illa uirtute, et in illa potes- } \\
\text { tate, in qua fuit Iesus } \\
\text { Christus, quando fuit adul- } \\
\text { tus et habuit perfectam ae- } \\
\text { tatem, in illa eadem sapien- } \\
\text { tia, potestate et uirtute fuit, } \\
\text { quamprimum fuit unitus } \\
\text { cum Filio Dei. }\end{array}$ \\
\hline VIII & VIII & VIII \\
\hline $\begin{array}{l}\text { [2] Illo tempore, quo do- } \\
\text { minus noster Iesus Chris- } \\
\text { tus aetatis erat annorum } \\
\text { triginta, incepit populo } \\
\text { praedicare, et plurima mi- }\end{array}$ & $\begin{array}{l}\text { [2] In illo tempore, quo } \\
\text { dominus Deus noster Iesus } \\
\text { Christus habuit aetatem tri- } \\
\text { ginta annorum, ipse prae- } \\
\text { dicabat populo Israelitico, }\end{array}$ & $\begin{array}{l}\text { [2] In illo tempore, quo } \\
\text { noster dominus Iesus } \\
\text { Christus habuit aetatem tri- } \\
\text { ginta annorum, et praedi- } \\
\text { cabat populo Israelis, et fa- }\end{array}$ \\
\hline
\end{tabular}




\begin{tabular}{|c|c|c|}
\hline $\begin{array}{l}\text { racula faciebat, et praedi- } \\
\text { cauit quasi per tres annos. } \\
\text { In illo tempore Iudaei inui- } \\
\text { di uolentes eum perdere } \\
\text { tractauerunt, quomodo ip- } \\
\text { sum perderent, diabolo ins- } \\
\text { tigante. }\end{array}$ & $\begin{array}{l}\text { et faciebat multa miracula, } \\
\text { accidit, quod Iudaei trac- } \\
\text { tauerunt de sua morte. }\end{array}$ & $\begin{array}{l}\text { ciebat multa miracula, ac- } \\
\text { cidit, quod Iudaei tracta- } \\
\text { bant suam mortem. }\end{array}$ \\
\hline VIII & VIII & VIII \\
\hline $\begin{array}{l}\text { [9] Postquam autem per- } \\
\text { cusserunt eum et in multis } \\
\text { illusissent, fecerunt eum to- } \\
\text { llere crucem suam usque } \\
\text { ad locum, ubi crucifixerunt } \\
\text { eum, et clauis confixerunt. } \\
\text { Deinde erexerunt crucem } \\
\text { in altum et stetit in cruce } \\
\text { suspensus, ut possent eum } \\
\text { aspicere omnes gentes. }\end{array}$ & $\begin{array}{l}\text { [9] Postquam uerberaue- } \\
\text { runt ipsum, fecerunt ei por- } \\
\text { tari crucem usque ad lo- } \\
\text { cum, ubi crucifixerunt } \\
\text { eum, et ipsum clauellaue- } \\
\text { runt in cruce. Et stabat pen- } \\
\text { dens in cruce, ut omnes ui- } \\
\text { derent eum. }\end{array}$ & $\begin{array}{l}\text { [9] Postquam illum fla- } \\
\text { gellauerunt, erexerunt cru- } \\
\text { cem, ut omnes illum uide- } \\
\text { rent. }\end{array}$ \\
\hline
\end{tabular}

3a. Expresión más breve $(M N)$ - Expresión más larga $(L-P)$

\begin{tabular}{|c|c|c|}
\hline XVIII & XVIII & XVIII \\
\hline $\begin{array}{l}\text { [3] Cogita, fili, quanta } \\
\text { puritas est in flore et in } \\
\text { anima uirtuosa, et cogita } \\
\text { quanta pollutio, quod ego } \\
\text { nominare uel scribere non } \\
\text { sum ausus, quia uerba non } \\
\text { possem dicere turpiora. }\end{array}$ & $\begin{array}{l}\text { [3] Dilige, fili, mundi- } \\
\text { tiem, quae est in flore et in } \\
\text { anima uirtuosa, et conside- } \\
\text { ra in magna immunditie et } \\
\text { turpitudine, quae sunt in } \\
\text { opere luxuriae, quae non } \\
\text { audeo nominare nec scribe- } \\
\text { re, nec turpiora uerba, quae } \\
\text { sunt, nominem neque scri- } \\
\text { bam. }\end{array}$ & $\begin{array}{l}\text { [3] Aestima, fili, mundi- } \\
\text { tiam, quae est in flore et in } \\
\text { uirtuosa anima, et cogita } \\
\text { magnam turpitudinem, } \\
\text { quae est in opere luxuriae, } \\
\text { quam non audeo nec nomi- } \\
\text { nare nec scribere, ut turpio- } \\
\text { ra uerba, quae sint, non no- } \\
\text { minem nec scribam. }\end{array}$ \\
\hline LIX & LIX & LIX \\
\hline $\begin{array}{l}\text { [7] Amabilis fili, maior } \\
\text { est Dei uoluntas quam tua, } \\
\text { et ideo conuenit, quod } \\
\text { Deus fortius tuam diligat } \\
\text { saluationem, quam tu; } \\
\text { unde propter hoc sua uo- } \\
\text { luntas conuenit suae potes- }\end{array}$ & $\begin{array}{l}\text { [7] Amabilis fili, maior } \\
\text { est uoluntas Dei, quam tua, } \\
\text { et ideo oportet, quod Deus } \\
\text { fortius diligat tuam salua- } \\
\text { tionem, quam facias tu; et } \\
\text { propter hoc uoluntas sua } \\
\text { conuenit cum posse suo, }\end{array}$ & $\begin{array}{l}\text { [7] Amabilis fili, uolun- } \\
\text { tas Dei est maior quam tua, } \\
\text { et ideo conuenit, quod } \\
\text { Deus fortius amet tuam sal- } \\
\text { uationem, quam tu illam } \\
\text { ames; unde sua uoluntas } \\
\text { conuenit cum sua potestate, }\end{array}$ \\
\hline
\end{tabular}




\begin{tabular}{|c|c|c|}
\hline $\begin{array}{l}\text { tati: cuicumque uult, sal- } \\
\text { uationem tribuit; si Deus } \\
\text { uolens saluare non salua- } \\
\text { ret non esset omnipotens. }\end{array}$ & $\begin{array}{l}\text { quod potest dare, cui uult, } \\
\text { saluationem; et cum tuum } \\
\text { uelle non habeat posse, } \\
\text { quod det tibi nec alteri sal- } \\
\text { uationem, nisi Deus plus } \\
\text { diligeret tuam saluationem, } \\
\text { quam tu ipse, esset minor } \\
\text { in uolendo quam in pos- } \\
\text { sendo. }\end{array}$ & $\begin{array}{l}\text { quae potest dare salua- } \\
\text { tionem, cui uult; et quia tua } \\
\text { uoluntas non habet potes- } \\
\text { tatem, quod det tibi uel al- } \\
\text { teri saluationem, etsi Deus } \\
\text { non plus amaret tuam sal- } \\
\text { uationem, quam tuipse, es- } \\
\text { set minor in uoluntate, } \\
\text { quam in potestate, et hoc } \\
\text { non est uerum. }\end{array}$ \\
\hline LXXVIII & LXXVIII & LXXVIII \\
\hline $\begin{array}{l}\text { [23] Medicus uolens cu- } \\
\text { rare infirmum per acciden- } \\
\text { tia, quae designantur, cog- } \\
\text { noscit, quae cura infirmo } \\
\text { sit necessaria. }\end{array}$ & $\begin{array}{l}\text { [23] Amabilis fili, medi- } \\
\text { cus habet intentionem cu- } \\
\text { randi infirmitatem, et ex } \\
\text { accidentibus, quae se ma- } \\
\text { nifestant propter infirmita- } \\
\text { tem, inquirit occasionem } \\
\text { infirmitatis; et quando ha- } \\
\text { bet notitiam infirmitatum, } \\
\text { tunc per contrariam occa- } \\
\text { sionem curat infirmum. }\end{array}$ & $\begin{array}{l}\text { [23] Amabilis fili, medi- } \\
\text { cus habet intentionem cu- } \\
\text { randi infirmitatem, et per } \\
\text { accidentia, quae se de- } \\
\text { monstrant per infirmitatem, } \\
\text { inquirit causam infirmita- } \\
\text { tis; et quando habet cogni- } \\
\text { tionem causae, tunc per } \\
\text { contrariam causam curat } \\
\text { infirmitatem. }\end{array}$ \\
\hline
\end{tabular}

\section{3b. Expresión más larga $(M N)$ — Expresió más breve $(L-P)$}

\begin{tabular}{|c|c|c|}
\hline LXXXIX & LXXXIX & LXXXIX \\
\hline $\begin{array}{l}\text { [1] Hypocrisia est finge- } \\
\text { re se uirtuosum exterius et } \\
\text { esse criminosum interius; } \\
\text { et hypocritae sunt sicut pa- } \\
\text { ries, qui exterius est albus } \\
\text { et pictus, et interius est } \\
\text { inepte factus et male com- } \\
\text { positus et male fundamen- } \\
\text { to. Et sicut trabes intus cor- } \\
\text { rosa et putrida et foris } \\
\text { picta, et sicut fructus pul- } \\
\text { cher exterius et intus tur- } \\
\text { pis, sic hypocritae exterius } \\
\text { sunt pulchri et intus pleni } \\
\text { uitiis et mendaciis. }\end{array}$ & $\begin{array}{l}\text { [1] Hypocrisis est simili- } \\
\text { tudo uirtutis in hoc, quod } \\
\text { est uitium occultum; et } \\
\text { ideo, fili, homines hypocri- } \\
\text { tae faciunt falsas similitu- } \\
\text { dines et uolunt uideri a } \\
\text { gentibus, quod sint boni, et } \\
\text { tamen sunt pleni uitiis et } \\
\text { defectibus. }\end{array}$ & $\begin{array}{l}\text { [1] Hypocrisis est simili- } \\
\text { tudo uirtutis in hoc, quod } \\
\text { est occultatum uitium; et } \\
\text { ideo, fili, homines hypocri- } \\
\text { tae faciunt falsas similitu- } \\
\text { dines et fingunt se coram } \\
\text { gentibus, quod sint boni et } \\
\text { sunt mali et pleni uitiis et } \\
\text { culpis. }\end{array}$ \\
\hline
\end{tabular}




\section{Singular / plural}

\begin{tabular}{|c|c|c|}
\hline IX & IX & IX \\
\hline $\begin{array}{l}\text { [5] [...] non tamen cre- } \\
\text { das, fili, quod Filius Dei } \\
\text { iterum ueniat in hunc mun- } \\
\text { dum ad liberandum pecca- } \\
\text { tores, qui resident in infer- } \\
\text { no. }\end{array}$ & $\begin{array}{l}\text { [5] [...] et credas, fili, } \\
\text { quod Filius Dei nunquam } \\
\text { ueniet alia uice deliberatum } \\
\text { peccatores, qui sunt in in- } \\
\text { ferno. }\end{array}$ & $\begin{array}{l}\text { [5] [...] et non credas, } \\
\text { fili, quod Filius Dei ullo } \\
\text { tempore ueniat ad liberan- } \\
\text { dum peccatores, qui sunt in } \\
\text { infernis. }\end{array}$ \\
\hline
\end{tabular}

\section{Verbo: infinitivo / ad+gerundio}

\begin{tabular}{|r|r|r|}
\hline VI & \multicolumn{1}{|c|}{ VI } & \multicolumn{1}{c|}{ VI } \\
[8] Fili, obligatus es cre- & $\begin{array}{l}\text { [8] Obligatus es, fili, ad } \\
\text { credendum his, quae tibi } \\
\text { cemnia, quae de con- } \\
\text { ceptione Dei Filii tibi dixi. } \\
\text { dico de conceptione Filii } \\
\text { Dei. }\end{array}$ & $\begin{array}{l}\text { crendum ista, quae dico } \\
\text { de conceptione Filii Dei. }\end{array}$ \\
\hline
\end{tabular}

\section{Verbo pasivo: compuesto / simple}

\begin{tabular}{|c|c|c|}
\hline IIII & IIII & IIII \\
\hline $\begin{array}{l}{[2][\ldots] \text { et propter hoc ex- }} \\
\text { pedit, quod I peccatum fo- } \\
\text { ret deuictum et superatum } \\
\text { per illum, qui magis con- } \\
\text { trarius est peccato, quam } \\
\text { per aliquod aliud posset } \\
\text { esse. }\end{array}$ & $\begin{array}{l}\text { [2] [...] et propter hoc } \\
\text { oportuit, quod peccatum } \\
\text { fuisset deuictum et supera- } \\
\text { tum per illum, qui magis } \\
\text { est contrarius peccato } \\
\text { quam aliquod aliud. }\end{array}$ & $\begin{array}{l}{[2][\ldots] \text { et ideo conuenit }} \\
\text { quod illud peccatum uince- } \\
\text { retur et superaretur per } \\
\text { illum, qui est magis contra- } \\
\text { rius peccato, quam omne } \\
\text { aliud. }\end{array}$ \\
\hline V & V & V \\
\hline $\begin{array}{l}\text { [1] Gloria, fili, est conti- } \\
\text { nua et frequens beatitudo } \\
\text { absque aliquo interuallo ad } \\
\text { laudandum illum, qui glo- } \\
\text { riam elargitur, quae conce- } \\
\text { ditur a domino Deo nostro, } \\
\text { qui gloriando in sua gloria } \\
\text { dat gloriam sanctis suis. }\end{array}$ & $\begin{array}{l}\text { [1] Gloria est, fili, conti- } \\
\text { nua et frequens benedictio } \\
\text { sine cessatione in laudan- } \\
\text { do illum, qui dat gloriam, } \\
\text { quae quidem gloria est } \\
\text { data per dominum Deum } \\
\text { nostrum, qui glorians in } \\
\text { sua gloria dat gloriam } \\
\text { sanctis gloriae. }\end{array}$ & $\begin{array}{l}\text { [1] Gloria, fili, est conti- } \\
\text { nua et frequens beatitudo } \\
\text { sine ulla cessatione ad lau- } \\
\text { dandum illum, qui dat glo- } \\
\text { riam, quae gloria datur per } \\
\text { nostrum dominum Deum, } \\
\text { qui gloriando in sua gloria } \\
\text { dat gloriam sanctis gloriae. }\end{array}$ \\
\hline
\end{tabular}




\section{Verbo: present de subjuntivo / futuro de indicativo}

\begin{tabular}{|c|c|c|}
\hline V & $\mathrm{V}$ & $\mathrm{V}$ \\
\hline $\begin{array}{l}\text { [9] Si tu, fili, ingrediaris } \\
\text { gloriam, ubicumque sis erit } \\
\text { gloria, et reperies gloriam } \\
\text { [...]. Scis quare? Quoniam } \\
\text { in omnibus locis gloriae est } \\
\text { glorificator et dominus glo- } \\
\text { riae sempiternae. }\end{array}$ & $\begin{array}{l}\text { [9] Si tu, fili, intres in } \\
\text { gloria, ubicumque sis ha- } \\
\text { bebis gloriam, et inuenies } \\
\text { gloriam. Et scis quare? } \\
\text { Quia in omnibus locis glo- } \\
\text { riae est glorificator et do- } \\
\text { minus gloriae. }\end{array}$ & $\begin{array}{l}\text { [9] Si tu, fili, intrabis in } \\
\text { gloriam, ubicumque sis ha- } \\
\text { bebis gloriam, et inuenies } \\
\text { gloriam. Et scis quare? } \\
\text { Ideo, quia in omnibus locis } \\
\text { gloriae est glorificator et } \\
\text { dominus gloriae. }\end{array}$ \\
\hline
\end{tabular}

\section{Verbo: presente de indicativo / presente de subjuntivo / presente de indicativo}

\begin{tabular}{|c|c|c|}
\hline V & V & V \\
$\begin{array}{c}\text { [1] Ideo, fili, si gloriam } \\
\text { uis habere... }\end{array}$ & $\begin{array}{c}\text { [1] Vnde, fili, si tu uelis } \\
\text { habere gloriam... }\end{array}$ & $\begin{array}{c}\text { [1] Vnde, fili, si tu uis } \\
\text { habere gloriam... }\end{array}$ \\
\hline
\end{tabular}

9. Verbo: Indicativo presente / pretérito perfecto / pretérito perfecto

\begin{tabular}{|l|l|c|}
\hline \multicolumn{1}{|c|}{ IIII } & \multicolumn{1}{|c|}{ IIII } & \multicolumn{1}{c|}{ IIII } \\
$\begin{array}{r}\text { [9] Fili, si tam malum est } \\
\text { peccare et esse Deoinoboe- } \\
\text { diens, quod pro solo uno } \\
\text { peccato in ira Dei sumus } \\
\text { omnes... }\end{array}$ & $\begin{array}{l}\text { [9] Si igitur ita mala res, } \\
\text { fili, sit peccatum et esse } \\
\text { inoboediens Deo, quod } \\
\text { propter unum peccatum } \\
\text { tantummodo fuimus omnes } \\
\text { in ira Dei... }\end{array}$ & $\begin{array}{l}\text { [9] Fili, si tam mala res } \\
\text { est pecare et esse inoboe- } \\
\text { diens Deo, quod per unum } \\
\text { peccatum tantum omnes } \\
\text { fuimus in ira Dei... }\end{array}$ \\
\hline
\end{tabular}

\section{Verbo: Indicativo presente / imperfecto / pretérito perfecto.}

\begin{tabular}{|c|c|c|}
\hline VIII & VIII & VIII \\
\hline $\begin{array}{l}\text { [12] [...] Sed propter } \\
\text { amorem uehementem, } \\
\text { quem erga nos habet, uo- } \\
\text { luit totum sanguinem suum } \\
\text { fundere. }\end{array}$ & $\begin{array}{l}\text { [12] [...] Sed propter } \\
\text { magnum amorem, quem } \\
\text { habebat erga nos, uoluit, } \\
\text { quod totus suus sanguis } \\
\text { fuisset effusus. }\end{array}$ & $\begin{array}{l}\text { [12] [...] Sed propter } \\
\text { magnum amorem, quem } \\
\text { erga nos habuit, uoluit, } \\
\text { quod suus totus sanguis ef- } \\
\text { fuderetur. }\end{array}$ \\
\hline
\end{tabular}




\section{Verbo: Infinitivo / Pluscuamperfecto de subjuntivo pasivo / Imperfec- to de subjuntivo pasivo.}

\begin{tabular}{|c|c|c|}
\hline VIII & VIII & VIII \\
\hline $\begin{array}{l}\text { [12] [...] Sed propter } \\
\text { amorem uehementem, } \\
\text { quem erga nos habet, uo- } \\
\text { luit totum sanguinem suum } \\
\text { fundere. }\end{array}$ & $\begin{array}{l}\quad[12][\ldots] \text { Sed propter } \\
\text { magnum amorem, quem } \\
\text { habebat erga nos, uoluit, } \\
\text { quod totus suus sanguis } \\
\text { fuisset effusus. }\end{array}$ & $\begin{array}{l}\text { [12] [...] Sed propter } \\
\text { magnum amorem, quem } \\
\text { erga nos habuit, uoluit, } \\
\text { quod suus totus sanguis ef- } \\
\text { fuderetur. }\end{array}$ \\
\hline
\end{tabular}

\section{Verbo: Indicativo perfecto / Indicativo pluscuamperfecto / Subjunti- vo presente}

\begin{tabular}{|c|c|c|}
\hline VIII & VIII & VIII \\
\hline $\begin{array}{l}\text { [18] Quid est istud, quod } \\
\text { pro seruo suo dominus } \\
\text { mori uoluit, et seruus pro } \\
\text { domino suo mortuus esse } \\
\text { non uult? }\end{array}$ & $\begin{array}{l}\text { [18] Quid est hoc, quod } \\
\text { dominus uoluerat mori pro } \\
\text { suo uasallo, et uasallus non } \\
\text { uelit mori pro suo domino? }\end{array}$ & $\begin{array}{l}\text { [18] Quid est hoc, quod } \\
\text { dominus uelit mori pro suo } \\
\text { seruo, et seruus non uelit } \\
\text { mori pro suo domino? }\end{array}$ \\
\hline
\end{tabular}

\section{Verbo: gerundio / participio presente / gerundio}

\begin{tabular}{|l|l|r|}
\hline \multicolumn{1}{|c|}{$\mathrm{V}$} & \multicolumn{1}{c|}{$\mathrm{V}$} & $\mathrm{V}$ \\
$\begin{array}{r}\text { [1] Gloria, fili, est conti- } \\
\text { nua et frequens beatitudo } \\
\text { absque aliquo interuallo ad } \\
\text { laudandum illum, qui glo- } \\
\text { riam elargitur, quae conce- } \\
\text { ditur a domino Deo nostro, } \\
\text { qui gloriando in sua gloria } \\
\text { dat gloriam sanctis suis. }\end{array}$ & $\begin{array}{l}\text { sine cessatione in laudan- } \\
\text { nua et frequens benedictio } \\
\text { do illum, qui dat gloriam, } \\
\text { quae quidem gloria est data } \\
\text { per dominum Deum nos- } \\
\text { trum, qui glorians in sua } \\
\text { gloria dat gloriam sanctis } \\
\text { gloriae. }\end{array}$ & $\begin{array}{l}\text { [1] Gloria, fili, est conti- } \\
\text { nua et frequens beatitudo } \\
\text { sine ulla cessatione ad lau- } \\
\text { dandum illum, qui dat glo- } \\
\text { riam, quae gloria datur per } \\
\text { nostrum dominum Deum, } \\
\text { qui gloriando in sua gloria } \\
\text { dat gloriam sanctis gloriae. }\end{array}$ \\
\hline
\end{tabular}




\section{Verbo: activa, indicativo imperfecto / pasiva, indicativo imperfecto / activa, subjuntivo imperfecto}

\begin{tabular}{|c|c|c|}
\hline VIII & VIII & VIII \\
\hline $\begin{array}{l}\text { [3] Quando autem ap- } \\
\text { propinquabat passio Iesu } \\
\text { Christi ad diem, quam } \\
\text { mori debuit... }\end{array}$ & $\begin{array}{l}\text { [3] Et quando appropin- } \\
\text { quabatur passio Iesu } \\
\text { Christi die, qua debebat } \\
\text { mori... }\end{array}$ & $\begin{array}{l}\text { [3] Cum appropinquaret } \\
\text { passio Iesu Christi, in die } \\
\text { qua debuit mori... }\end{array}$ \\
\hline
\end{tabular}

\section{Oración de infinitivo / completiva con quod}

\begin{tabular}{|c|c|c|}
\hline V & V & V \\
\hline $\begin{array}{l}\text { [1] Ideo, fili, si gloriam } \\
\text { uis habere, oportet te cre- } \\
\text { dere, quod Deus sit glorifi- } \\
\text { cator beatorum paradisi, et } \\
\text { quod illi in sua gloria glo- } \\
\text { rientur, et quod Deus cum } \\
\text { sua gloria illos glorificet in } \\
\text { aeternum. }\end{array}$ & $\begin{array}{l}\text { [1] Vnde, fili, si tu uelis } \\
\text { habere gloriam, credere te } \\
\text { oportet, quod Deus sit glo- } \\
\text { rificator beatorum paradi- } \\
\text { si, et quod ipsi sunt glorifi- } \\
\text { cati in sua gloria, et quod } \\
\text { Deus glorificat eos cum } \\
\text { suamet gloria. }\end{array}$ & $\begin{array}{l}\text { [1] Vnde, fili, si tu uis } \\
\text { habere gloriam, conuenit, } \\
\text { quod credas, quod Deus sit } \\
\text { glorificator beatorum para- } \\
\text { disi, et quod illi glorificen- } \\
\text { tur in sua gloria, et quod } \\
\text { Deus illos glorificet cum } \\
\text { suamet gloria. }\end{array}$ \\
\hline VI. De conceptione & $\begin{array}{l}\text { De conceptione. Sextum } \\
\text { capitulum }\end{array}$ & Cap. 6. De conceptione \\
\hline $\begin{array}{l}\text { [1] Oportet, fili, quod tu } \\
\text { credas in conceptionem } \\
\text { domini Dei nostri Iesu } \\
\text { Christi... }\end{array}$ & $\begin{array}{l}\text { [1] Credere te oportet, } \\
\text { fili, in conceptionem domi- } \\
\text { ni Dei nostri Iesu Christi... }\end{array}$ & $\begin{array}{l}\text { [1] Fili, conuenit, quod } \\
\text { credas in conceptionem } \\
\text { nostri domini Dei Iesu } \\
\text { Christi... }\end{array}$ \\
\hline
\end{tabular}

\section{Verbo: Oración de infinitivo pasivo / completiva activa / completiva pasiva}

\begin{tabular}{|l|l|l|}
\hline \multicolumn{1}{|c|}{ VIII } & \multicolumn{1}{|c|}{ VIII } & \multicolumn{1}{c|}{ VIII } \\
$\begin{array}{l}\text { [11] [...] Sed quia mors } \\
\text { sua erat necessaria ad } \\
\text { suum populum redimen- } \\
\text { dum, hoc ideo cruciari uo- } \\
\text { luit et occidi. }\end{array}$ & $\begin{array}{l}\text { [11] [...] Sed quia sua } \\
\text { mors erat necessaria ad sa- } \\
\text { luandum sum populum, } \\
\text { ideoluit pati, quod ho- } \\
\text { mines tormentarent et in- } \\
\text { terficerent eum. }\end{array}$ & $\begin{array}{l}\text { [11] [...] Sed quia sua } \\
\text { mors erat necessaria ad sa- } \\
\text { luandum sum populum, } \\
\text { ideo uoluit permittere, } \\
\text { quod tormentaretur et oc- } \\
\text { cideretur. }\end{array}$ \\
\hline
\end{tabular}




\section{Verbo: Oración de infinitivo pasivo / Imperfecto de subjuntivo activo / Imperfecto de subjuntivo pasivo}

\begin{tabular}{|c|c|c|}
\hline VIII & VIII & VIII \\
\hline $\begin{array}{l}\text { [13] Dilecte fili, si uis in } \\
\text { gloria uiuere, lugeas mor- } \\
\text { tem tui domini Iesu Christi; } \\
\text { et si flere nequis, non tan- } \\
\text { tum eum diligis, quantum } \\
\text { te diligit tua mater, quae } \\
\text { utique fleret, si coram se } \\
\text { cruciari uel interfici te ui- } \\
\text { deret. }\end{array}$ & $\begin{array}{l}\text { [13] Dilecte fili, si uelis } \\
\text { uiuere in gloria, plora mor- } \\
\text { tem tui domini Iesu Christi; } \\
\text { et nisi posses plorare, non } \\
\text { eum tantum diligis, quan- } \\
\text { tum tua mater te diligit, } \\
\text { quae ploraret, si quis co- } \\
\text { ram ea te interficeret et } \\
\text { tormentaret. }\end{array}$ & $\begin{array}{l}\text { [13] Amabilis fili, si uis } \\
\text { uiuere in gloria, plora mor- } \\
\text { tem tui domini Iesu Christi; } \\
\text { et si non potes plorare, non } \\
\text { amas illum tantum, quan- } \\
\text { tum tua mater te amat, } \\
\text { quae ploraret, si ante illam } \\
\text { occidereris et cruciareris. }\end{array}$ \\
\hline
\end{tabular}

\section{Coordinada copulativa / giro final / subordinada de relativo}

\begin{tabular}{|c|c|c|}
\hline$X$ & $X$ & $X$ \\
\hline $\begin{array}{l}\text { [4] Item, quando aposto- } \\
\text { li stabant inclusi in quadam } \\
\text { camera et ianuae essent } \\
\text { clausae, dominus Iesus } \\
\text { Christus apparuit eis ad os- } \\
\text { tendendum, quod surrexe- } \\
\text { rat corpore glorificato, } \\
\text { quod quidem corpus non } \\
\text { poterat loco seu obiecto } \\
\text { aliquo impediri; et ad os- } \\
\text { tendendum, quod ipse ue- } \\
\text { racius erat homo, escam } \\
\text { petiit et comedit. }\end{array}$ & $\begin{array}{l}\text { [4] Dum apostoli starent } \\
\text { in una camera ianuis clau- } \\
\text { sis, dominus noster Iesus } \\
\text { Christus apparuit eis ad os- } \\
\text { tendendum, quod ipse re- } \\
\text { surrexerat cum corpore } \\
\text { glorificato, quod non habet } \\
\text { impedimentum transeundi } \\
\text { ubique; et ad demonstran- } \\
\text { dum, quod ipse erat uerus } \\
\text { homo, petiit ad comenden- } \\
\text { dum. }\end{array}$ & $\begin{array}{l}\text { [4] Dum apostoli erant in } \\
\text { una camera et portae erant } \\
\text { clausae, noster dominus Ie- } \\
\text { sus Christus apparuit illis } \\
\text { ad demonstrandum, quod } \\
\text { ipse resurrexisset cum glo- } \\
\text { rificato corpore, quod non } \\
\text { habet impedimentum trans- } \\
\text { eundi per omne locum; et } \\
\text { ad demonstrandum, quod } \\
\text { ipse uere esset homo, pe- } \\
\text { tiit, quod manducaret. }\end{array}$ \\
\hline
\end{tabular}

\section{Interrogativa indirecta: Utrum...aut / uel...uel / an...uel}

\begin{tabular}{|c|c|c|}
\hline VIII & VIII & VIII \\
\hline $\begin{array}{l}\text { [19] Scires, fili, respon- } \\
\text { dere, quae mors esset me- } \\
\text { lior aut dulcior, utrum } \\
\text { mors aegritudinis aut amo- } \\
\text { ris? }\end{array}$ & $\begin{array}{l}\text { [19] Sciesne mihi res- } \\
\text { pondere, fili, qualis mors } \\
\text { est melior nec dulcior, uel } \\
\text { mori amore uel infirmita- } \\
\text { te? }\end{array}$ & $\begin{array}{l}\text { [19] Sciresne mihi res- } \\
\text { pondere, fili, quae mors sit } \\
\text { magis dulcis et melior, an } \\
\text { mori per amorem uel per } \\
\text { infirmitatem? }\end{array}$ \\
\hline
\end{tabular}




\section{Oración completiva: introducida por ut / introducida por quod}

\begin{tabular}{|c|c|c|}
\hline IIII & IIII & IIII \\
\hline $\begin{array}{l}\text { [5] Omnes, qui morie- } \\
\text { bantur, ibant ad ignem in- } \\
\text { ferni, donec placuit summo } \\
\text { Patri, ut suus Filius carnem } \\
\text { sumeret in nostra domina } \\
\text { sancta Maria, per gratiam } \\
\text { sancti Spiritus. }\end{array}$ & $\begin{array}{l}\text { [5] Omnes illi, qui inde } \\
\text { moriebantur, ibant in ig- } \\
\text { nem infernalem, donec pla- } \\
\text { cuit superno Patri, quod } \\
\text { suus Filius assumeret car- } \\
\text { nem in nostra domina } \\
\text { sancta Maria gratia sancti } \\
\text { Spiritus. }\end{array}$ & $\begin{array}{l}\text { [5] Omnes illi, qui mo- } \\
\text { riebantur, ibant in inferna- } \\
\text { lem ignem, quousque pla- } \\
\text { cuit supremo Patri, quod } \\
\text { suus Filius assumeret car- } \\
\text { nem in nostra domina } \\
\text { sancta Maria per gratiam } \\
\text { sanctus Spiritus. }\end{array}$ \\
\hline VI & VI & VI \\
\hline $\begin{array}{l}\text { [3] Has salutes, fili, di- } \\
\text { cas saepe uirgini gloriosae, } \\
\text { quia maius placitum et } \\
\text { maior honor, quem impen- } \\
\text { dere ualeat sibi homo est, } \\
\text { ut salutetur per easdem sa- } \\
\text { lutes, quas angelus Gabriel } \\
\text { attulit ei a domino Deo } \\
\text { nostro. }\end{array}$ & $\begin{array}{l}\text { [3] Istas salutes, fili, dic } \\
\text { saepe uirgini gloriosae, } \\
\text { quia maius placitum et } \\
\text { maiorem honorem, quos } \\
\text { possis ei facere, est, quod } \\
\text { homo salutet eam per illas- } \\
\text { met salutes, quas sanctus } \\
\text { Gabriel portauit ei de do- } \\
\text { mino Deo nostro. }\end{array}$ & $\begin{array}{l}\text { [3] Fili, has salutes saepe } \\
\text { dicas gloriosae uirgini, quia } \\
\text { maius placitum et maior ho- } \\
\text { nor, quem homo illi potest } \\
\text { facere, est, quod homo illam } \\
\text { salutet per illas easdem sa- } \\
\text { lutationes, quas sanctus an- } \\
\text { gelus Gabriel illi attulit de } \\
\text { nostro domino Deo. }\end{array}$ \\
\hline
\end{tabular}

\section{Absque+Ablativo / Quin+Subjuntivo}

\begin{tabular}{|l|c|c|}
\hline \multicolumn{1}{|c|}{ IIII } & IIII & IIII \\
$\begin{aligned} \text { [6] In illa puella fuit Dei } \\
\text { Filius incarnatus, et ortus } \\
\text { fuit, ipsa manente uirgine, } \\
\text { nec eius fuit uirginitas uio- } \\
\text { lata. }\end{aligned}$ & $\begin{array}{l}\text { Dei fuit incarnatus, et na- } \\
\text { tus fuit ipsa uirgine exis- } \\
\text { tente absque corruptione } \\
\text { nec perditione uirginitatis. }\end{array}$ & $\begin{array}{l}\text { l6] In illa domicella Fi- } \\
\text { neitus ipsa existente uirgi- } \\
\text { ne, quin corrumperetur et } \\
\text { perderet suam uirginita- }\end{array}$ \\
\hline
\end{tabular}

\section{Absque / sine}

\begin{tabular}{|c|c|c|}
\hline $\mathrm{V}$ & $\mathrm{V}$ & $\mathrm{V}$ \\
$\begin{array}{c}\text { [1] Gloria, fili, est conti- } \\
\text { nua et frequens beatitudo } \\
\text { absque aliquo interuallo... }\end{array}$ & $\begin{array}{l}\text { [1] Gloria est, fili, conti- } \\
\text { nua et frequens benedictio } \\
\text { sine cessatione... }\end{array}$ & $\begin{array}{l}\text { nua et frequens beatitudo } \\
\text { sine ulla cessatione... }\end{array}$ \\
\hline
\end{tabular}




\section{Construcción final: si / an}

\begin{tabular}{|c|c|c|}
\hline $\mathrm{V}$ & $\mathrm{V}$ & V \\
\hline $\begin{array}{l}\text { [11] Et si propter glo- } \\
\text { riam huius mundi alterius } \\
\text { saeculi gloriam uilipendis, } \\
\text { pone digitum tuum in ca- } \\
\text { minum, et tempta, si pote- } \\
\text { ris aeternum ignem perpe- } \\
\text { tuo sustinere, quem } \\
\text { damnati miseri patiuntur, } \\
\text { quoniam illum oportebit te } \\
\text { pati, si contempseris glo- } \\
\text { riam domini Dei nostri. }\end{array}$ & $\begin{array}{l}\text { [11] Et si pro gloria is- } \\
\text { tius mundi despicias glo- } \\
\text { riam alterius, fili, pone } \\
\text { tuum digitum in igne, et } \\
\text { tempta, si posses sustinere } \\
\text { ignem infernalem perpetue, } \\
\text { quem sustinent damnati, } \\
\text { quia illum ignem te opor- } \\
\text { tebit sustinere, si despicias } \\
\text { gloriam nostri domini Dei. }\end{array}$ & $\begin{array}{l}\text { [11] Et si tu, propter glo- } \\
\text { riam huius mundi contem- } \\
\text { nis gloriam alterius mundi, } \\
\text { pone tuum digitum in ig- } \\
\text { nem, et tempta, an perpe- } \\
\text { tuo poteris sustinere infer- } \\
\text { nalem ignem, quem } \\
\text { sustinent damnati, quia tibi } \\
\text { conuenit sustinere illum ig- } \\
\text { nem, si contemnis gloriam } \\
\text { nostri domini Dei. }\end{array}$ \\
\hline
\end{tabular}

\section{Construcción final: ut+subjuntivo / gerundio en genitivo / gerundio en acusativo}

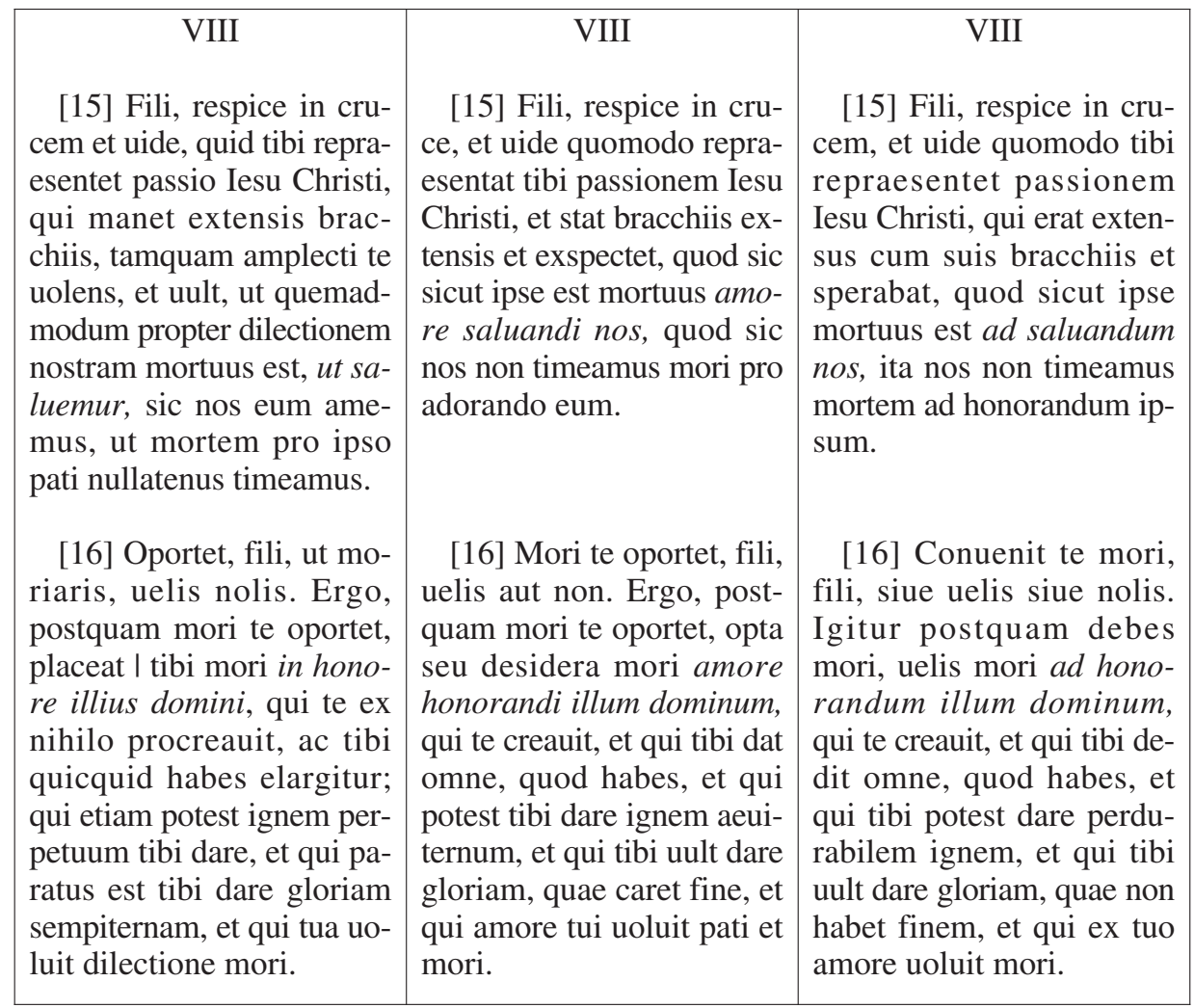




\begin{tabular}{|c|c|c|}
\hline XLI & XLI & XLI \\
\hline $\begin{array}{l}\text { [7] Amabilis fili, hic } \\
\text { mundus locus est ueniae et } \\
\text { miserendi, quia in alio sae- } \\
\text { culo uenia nequit dari; quia } \\
\text { si daemones et peccatores, } \\
\text { qui sunt in inferno, possent } \\
\text { amare misericordiam, om- } \\
\text { nes de inferno flagellis exi- } \\
\text { rent, et per uoluntatem mi- } \\
\text { serendi essent beati } \\
\text { beatitudine sempiterna. }\end{array}$ & $\begin{array}{l}\text { [7] Amabilis fili, iste } \\
\text { mundus est locus parcendi } \\
\text { et misericordiam habendi, } \\
\text { quia in alio saeculo nemo } \\
\text { potest parcere; quia si om- } \\
\text { nes daemones et peccato- } \\
\text { res, qui sunt in inferno, } \\
\text { possent habere uoluntatem } \\
\text { amandi misericordiam, } \\
\text { omnes exirent a tormentis } \\
\text { infernalibus, et propter uo- } \\
\text { luntatem misericordem es- } \\
\text { sent beati in perpetua beati- } \\
\text { tudine. }\end{array}$ & $\begin{array}{l}\text { [7] Amabilis fili, hic } \\
\text { mundus est locus remitten- } \\
\text { di et habendi misericor- } \\
\text { diam, quia homo non potest } \\
\text { remittere in alio saeculo; } \\
\text { nam si omnes daemones et } \\
\text { peccatores, qui sunt in in- } \\
\text { ferno, possent habere uo- } \\
\text { luntatem ad amandum mi- } \\
\text { sericordiam, omnes exirent } \\
\text { de infernalibus tormentis et } \\
\text { per misericordiosam uolun- } \\
\text { tatem essent beati in perdu- } \\
\text { rabili beatitudine. }\end{array}$ \\
\hline
\end{tabular}

\section{Gerundio con propter / pro / ad}

\begin{tabular}{|c|c|c|}
\hline \multicolumn{1}{|c|}{ IIII } & IIII & \multicolumn{1}{c|}{ IIII } \\
$\begin{array}{c}\text { [9] [...] et propter illud } \\
\text { peccatum delendum Filium } \\
\text { Dei oportuit incarnari... }\end{array}$ & $\begin{array}{l}\text { [9] [...] et pro delendo } \\
\text { illud peccatum Filius Dei } \\
\text { uoluit inacarnari... }\end{array}$ & $\begin{array}{l}\text { [9] [...] et ad delendum } \\
\text { illud peccatum Filius Dei } \\
\text { uoluit incarnari... }\end{array}$ \\
\hline
\end{tabular}

\section{Participio presente / Oración subordinada de relativo}

\begin{tabular}{|c|c|c|}
\hline IX & IX & IX \\
\hline $\begin{array}{l}\text { [5] Si uno peccato Adae } \\
\text { sanctae animae propheta- } \\
\text { rum peccato non consen- } \\
\text { tientes tanto tempore stete- } \\
\text { runt in inferno, et omni } \\
\text { tempore stetissent ni Filius } \\
\text { Dei aduenisset.... }\end{array}$ & $\begin{array}{l}\text { [5] Si pro uno peccato } \\
\text { Adae animae sanctorum } \\
\text { prophetarum, quae non } \\
\text { consentierunt peccato, } \\
\text { manserunt tamdiu ita lon- } \\
\text { go tempore in inferno, et } \\
\text { semper mansissent, si Fi- } \\
\text { lius Dei non uenisset... }\end{array}$ & $\begin{array}{l}\text { [5] Si propter unum pec- } \\
\text { catum Adae animae pro- } \\
\text { phetarum, quae non con- } \\
\text { senserunt peccato, tam } \\
\text { longo tempore fuerunt in } \\
\text { inferno, et omni tempore in } \\
\text { illo fuissent, nisi Filius Dei } \\
\text { uenisset... }\end{array}$ \\
\hline
\end{tabular}




\section{Ablativo absoluto / coordinada copulativa}

\begin{tabular}{|l|l|l|}
\hline \multicolumn{1}{|c|}{ X } & \multicolumn{1}{|c|}{ X } & \multicolumn{1}{c|}{ X } \\
$\begin{array}{l}\text { [4] Item, quando aposto- } \\
\text { li stabant inclusi in quadam } \\
\text { camera et ianuae essent } \\
\text { clausae }\end{array}$ & $\begin{array}{l}\text { [4] Dum apostoli starent } \\
\text { in una camera ianuis clau- } \\
\text { sis.. }\end{array}$ & $\begin{array}{l}\text { [4] Dum apostoli erant in } \\
\text { unamera et portae erant } \\
\text { clausae }\end{array}$ \\
\hline
\end{tabular}

\section{Concordancia del relativo con el antecedente: con el más próximo / con los dos}

\begin{tabular}{|c|c|c|}
\hline VI & VI & VI \\
\hline $\begin{array}{l}\text { [3] Has salutes, fili, di- } \\
\text { cas saepe uirgini gloriosae, } \\
\text { quia maius placitum et } \\
\text { maior honor, quem impen- } \\
\text { dere ualeat sibi homo est, } \\
\text { ut salutetur per easdem sa- } \\
\text { lutes, quas angelus Gabriel } \\
\text { attulit ei a domino Deo } \\
\text { nostro. }\end{array}$ & $\begin{array}{l}\text { [3] Istas salutes, fili, dic } \\
\text { saepe uirgini gloriosae, } \\
\text { quia maius placitum et } \\
\text { maiorem honorem, quos } \\
\text { possis ei facere, est, quod } \\
\text { homo salutet eam per illas- } \\
\text { met salutes, quas sanctus } \\
\text { Gabriel portauit ei de do- } \\
\text { mino Deo nostro. }\end{array}$ & $\begin{array}{l}\text { [3] Fili, has salutes saepe } \\
\text { dicas gloriosae uirgini, } \\
\text { quia maius placitum et } \\
\text { maior honor, quem homo } \\
\text { illi potest facere, est, quod } \\
\text { homo illam salutet per illas } \\
\text { easdem salutationes, quas } \\
\text { sanctus angelus Gabriel illi } \\
\text { attulit de nostro domino } \\
\text { Deo. }\end{array}$ \\
\hline
\end{tabular}

\section{In+ablativo - In+acusativo}

\begin{tabular}{|c|c|c|}
\hline \multicolumn{1}{|c|}{ IIII } & IIII & IIII \\
$\begin{array}{c}\text { [3] [...] et iste labor, } \\
\text { quem tu uides, cecidit in } \\
\text { nobis ac inter Deum et hu- } \\
\text { manum genus discordia } \\
\text { fuit facta. }\end{array}$ & $\begin{array}{l}\text { [3] [...] ideo incidit ista } \\
\text { mors et iste labor, quem tu } \\
\text { uides, in nobis aliis, et fuit } \\
\text { facta discordia inter Deum } \\
\text { et humanum genus. }\end{array}$ & $\begin{array}{r}\text { [3] [...] propter hoc ista } \\
\text { mors et iste labor, quem ui- } \\
\text { des, cecidit in nos, et fuit } \\
\text { facta discordia inter Deum } \\
\text { et humanum genus. }\end{array}$ \\
\hline
\end{tabular}

\section{Dirección: $a d+$ Acusativo / in+ Acusativo}

\begin{tabular}{|l|c|c|}
\hline \multicolumn{1}{|c|}{ IIII } & \multicolumn{1}{|c|}{ IIII } & IIII \\
$\begin{array}{c}\text { [5] Omnes, qui morie- } \\
\text { bantur, ibant ad ignem in- } \\
\text { ferni... }\end{array}$ & $\begin{array}{l}\text { [5] Omnes illi, qui inde } \\
\text { moriebantur, ibant in ig- } \\
\text { nem infernalem... }\end{array}$ & $\begin{array}{c}\text { [5] [5] Omnes illi, qui } \\
\text { moriebantur, ibant in infer- } \\
\text { nalem ignem... }\end{array}$ \\
\hline
\end{tabular}




\section{1. ad+Acusativo / Ablativo sin preposición / in+Ablativo}

\begin{tabular}{|l|r|r|}
\hline VIII & VIII & \multicolumn{1}{c|}{ VIII } \\
$\begin{array}{c}\text { [3] Quando autem ap- } \\
\text { propinquabat passio Iesu } \\
\begin{array}{l}\text { Christi ad diem, quam } \\
\text { mori debuit... }\end{array}\end{array}$ & $\begin{array}{l}\text { [3] Et quabando appropin- } \\
\text { ti die, qua debsio Iesu Chris- }\end{array}$ & $\begin{array}{c}\text { [3] Cum appropinquaret } \\
\text { passio Iesu Christi in die, } \\
\text { qua debuit mori... }\end{array}$ \\
\hline
\end{tabular}

\section{In+Ablativo / Ablativo sin preposición / In+Ablativo}

\begin{tabular}{|c|c|r|}
\hline IX & IX & IX \\
$\begin{array}{r}\text { [1] In tempore propheta- } \\
\text { rum et sanctorum homi- } \\
\text { num et sanctorum patrum... }\end{array}$ & $\begin{array}{l}\text { [1] Tempore propheta- } \\
\text { rum, sanctorum hominum } \\
\text { et sanctorum patrum... }\end{array}$ & $\begin{array}{r}\text { [1] In tempore propheta- } \\
\text { rum et sanctorum patrum... }\end{array}$ \\
\hline
\end{tabular}

\section{Dativo / Ad+Acusativo}

\begin{tabular}{|c|c|c|}
\hline VI & VI & VI \\
\hline $\begin{array}{l}\text { [2] In principio, quando } \\
\text { placuit domino Deo nostro } \\
\text { se humiliare, ut suum po- } \\
\text { pulum recrearet, ipse misit } \\
\text { dominae nostrae sanctae } \\
\text { Mariae angelum Gabrie- } \\
\text { lem. }\end{array}$ & $\begin{array}{l}\text { [2] In principio, quando } \\
\text { placuit domino Deo nostro, } \\
\text { qui se uoluit humiliare ad } \\
\text { recreandum suum popu- } \\
\text { lum, misit angelum Ga- } \\
\text { brielem dominae nostrae } \\
\text { sanctae Mariae. }\end{array}$ & $\begin{array}{l}\text { [2] In principio, quando } \\
\text { placuit nostro domino Deo, } \\
\text { quod se uoluerit humiliare } \\
\text { ad recreandum suum popu- } \\
\text { lum, misit sanctum angelum } \\
\text { Gabrielem ad nostram do- } \\
\text { minam sanctam Mariam. }\end{array}$ \\
\hline
\end{tabular}

\section{Medio: Per+Acusativo / ablativo}

\begin{tabular}{|c|c|c|}
\hline IIII & IIII & IIII \\
\hline $\begin{array}{l}\text { [5] Vnde tunc Filius Dei } \\
\text { per suam sublimem pieta- } \\
\text { tem uenit in quandam puel- } \\
\text { lam, I nomine Mariam, de } \\
\text { genere Dauid. }\end{array}$ & $\begin{array}{l}\text { [5] Et tunc Filius Dei sua } \\
\text { magna pietate uenit in qua- } \\
\text { dam puella uirgine, quae } \\
\text { uocabatur nostra domina } \\
\text { sancta Maria, quae fuit de } \\
\text { stirpe Dauid. }\end{array}$ & $\begin{array}{l}\text { [5] Vnde tunc Filius Dei } \\
\text { per suam magnam pieta- } \\
\text { tem uenit in unam domi- } \\
\text { nam uirginem, quae appe- } \\
\text { llatur nostra domina sancta } \\
\text { Maria, quae fuit de stirpe } \\
\text { Dauid. }\end{array}$ \\
\hline
\end{tabular}




\section{Pro+gerundio - Ad+gerundio}

\begin{tabular}{|c|c|c|}
\hline III & III & III \\
\hline $\begin{array}{l}\text { [14] Deus creauit homini } \\
\text { equum ad equitandum, et } \\
\text { ancipitrem ad uenandum, } \\
\text { mutonem ad comedendum, } \\
\text { lanam ad induendum, et } \\
\text { boues ad culturam, et ig- } \\
\text { nem ad calefaciendum et } \\
\text { illuminandum, et cuncta } \\
\text { alia creauit Deus ad ser- } \\
\text { uiendum homini. }\end{array}$ & $\begin{array}{l}\text { [14] Deus creauit homini } \\
\text { equum pro equitando, et } \\
\text { falconem pro uenando, et } \\
\text { ouem pro comedendo, et } \\
\text { lanam pro uestiendo, et ig- } \\
\text { nem pro calefaciendo, et } \\
\text { bouem pro arando, et om- } \\
\text { nes alias creaturas creauit } \\
\text { Deus ad seruiendum homi- } \\
\text { ni. }\end{array}$ & $\begin{array}{l}\text { [14] Deus creauit homini } \\
\text { equum ad equitandum, et } \\
\text { accipitrem ad uenandum, } \\
\text { et arietem ad comedendum, } \\
\text { et lanam ad uestiendum, et } \\
\text { ignem ad calefaciendum, et } \\
\text { bouem ad arandum, et om- } \\
\text { nes alias creaturas Deus } \\
\text { creauit ad seruiendum ho- } \\
\text { mini. }\end{array}$ \\
\hline
\end{tabular}

\section{Completiva introducida por $u t$ / pro+gerundio / ad+gerundio}

\begin{tabular}{|c|c|c|}
\hline \multicolumn{1}{|c|}{ VII } & VII \\
$\begin{array}{l}\text { [4] [...]Filius Dei natus } \\
\text { et peccatum. }\end{array}$ & $\begin{array}{c}\text { VII } \\
\text { [4] [...] Et Filius Dei na- } \\
\text { tus est pro delendo pecca- } \\
\text { tum et culpam. }\end{array}$ & $\begin{array}{l}\text { [4] [...] Et Filius Dei fuit } \\
\text { natus ad delendum et des- } \\
\text { truendum culpam et pecca- } \\
\text { tum. }\end{array}$ \\
$\begin{array}{c}\text { [7] [...] Ipse tamen uene- } \\
\text { rat, ut saluaret eos et eri- } \\
\text { peret } \text { a diaboli potestate. }\end{array}$ & $\begin{array}{l}\text { VIII } \\
\text { pro saluando eos et pro ex- } \\
\text { trahendo eos a potestate } \\
\text { diaboli. }\end{array}$ & $\begin{array}{l}\text { VII saluandum illos, et ad } \\
\text { eripiendum illos de potes- } \\
\text { tate diaboli. }\end{array}$ \\
\hline
\end{tabular}

\section{Ad+gerundio (acusativo) / In+gerundio (ablativo)}

\begin{tabular}{|l|c|c|}
\hline \multicolumn{1}{|c|}{$\mathrm{V}$} & $\mathrm{V}$ & \multicolumn{1}{c|}{$\mathrm{V}$} \\
$\begin{array}{l}\text { [1] Gloria, fili, est conti- } \\
\text { nua et frequens beatitudo } \\
\text { absque aliquo interuallo ad } \\
\text { laudandum illum, qui glo- } \\
\text { riam elargitur... }\end{array}$ & $\begin{array}{l}\text { [1] Gloria est, fili, conti- } \\
\text { nua et frequens benedictio } \\
\text { sine cessatione in laudando } \\
\text { illum, qui dat gloriam... }\end{array}$ & $\begin{array}{l}\text { [1] Gloria, fili, est conti- } \\
\text { nua et frequens beatitudo } \\
\text { sine ulla cessatione ad lau- } \\
\text { dandum illum, qui dat glo- } \\
\text { riam... }\end{array}$ \\
& & \\
\hline
\end{tabular}




\begin{tabular}{|c|c|c|}
\hline VI & VI & VI \\
\hline $\begin{array}{l}\text { [12] Cum Filius caeles- } \\
\text { tis et summus tam te hono- } \\
\text { rauerit in eo, quod naturam } \\
\text { humanam sumpsit similem } \\
\text { tuae naturae, amabilis fili, } \\
\text { consulo tibi, deposcor, et } \\
\text { praecipio, quantum pos- } \\
\text { sum, ut ponas omnes uires } \\
\text { tuas ad cognoscendum, } \\
\text { amandum, honorandum, } \\
\text { laudandum et seruiendum } \\
\text { Iesum Christum dominum } \\
\text { nostrum, ut omnia uerba } \\
\text { tua, uita tua, sint gloriae } \\
\text { Deo grata. }\end{array}$ & $\begin{array}{l}\text { [12] Cum Filius caeles- } \\
\text { tis supernus honorauerit te } \\
\text { tantum in hoc, quod cepit } \\
\text { naturam humanam similem } \\
\text { tuae, dilecte fili, ego do tibi } \\
\text { consilium, et precor te, et } \\
\text { tibi praecipio, ut carius } \\
\text { possum, quod tu omnes ui- } \\
\text { res tuas ponas in cognos- } \\
\text { cendo, amando, honoran- } \\
\text { do et seruiendo domino } \\
\text { nostro Iesu Christo, ut tuis } \\
\text { uerbis et tua uita et tuis } \\
\text { operibus Deo gloriae sis } \\
\text { gratus. }\end{array}$ & $\begin{array}{l}\text { [12] Cum caelestis su- } \\
\text { premus Filius te tantum ho- } \\
\text { norauerit in hoc, quod as- } \\
\text { sumpserit humanam } \\
\text { naturam similem tuae, } \\
\text { amabilis fili, do tibi consi- } \\
\text { lium, et precor, et praeci- } \\
\text { pio, quantum possum, } \\
\text { quod ponas omnes tuas ui- } \\
\text { res ad cognoscendum, } \\
\text { amandum et honorandum } \\
\text { et laudandum nostrum do- } \\
\text { minum Iesum Christum, et } \\
\text { seruiendum illi, ut tua uer- } \\
\text { ba et tua uita et tua opera } \\
\text { sint grata Deo gloriae. }\end{array}$ \\
\hline
\end{tabular}

38. Ablativo con de / con a (ab)

\begin{tabular}{|c|c|c|}
\hline IIII & IIII & IIII \\
$\begin{array}{c}\text { [6] De illa uirgine natus } \\
\text { fuit Deus et homo simul... }\end{array}$ & $\begin{array}{c}\text { [6] Ab illa puella } \text { natus } \\
\text { fuit Deus et homo simul... }\end{array}$ & $\begin{array}{l}\text { [6] De illa domicella na- } \\
\text { tus est Deus et homo insi- } \\
\text { mul... }\end{array}$ \\
\hline
\end{tabular}

\section{A quo / De quo}

\begin{tabular}{|c|c|c|}
\hline XXXII & XXXII & XXXII \\
\hline $\begin{array}{l}\text { [4] Si mala mulier uel } \\
\text { concupiscentia huius mun- } \\
\text { di tibi consulit, quod plus } \\
\text { quam Deum ipsam diligas, } \\
\text { Spiritus sanctus tibi consu- } \\
\text { lit plus quam omnia Deum } \\
\text { te diligere; et si tu, fili, } \\
\text { prauae mulieris credas } \\
\text { consilio, tu mittis in cap- } \\
\text { tionem infernalis carceris } \\
\text { tuum corpus, a quo ullo } \\
\text { tempore non exibis. }\end{array}$ & $\begin{array}{l}\text { [4] Si mala foemina tibi } \\
\text { consulat, quod eam diligas } \\
\text { plus quam Deum, sanctus } \\
\text { Spiritus tibi dat pro consi- } \\
\text { lio, quod ames plus Deum } \\
\text { quam cetera; et si tu, fili, } \\
\text { credas consilio malae mu- } \\
\text { lieris, noueris, quod tu in- } \\
\text { carceras tuum corpus in } \\
\text { carcere infernali, a quo } \\
\text { nunquam exibis. }\end{array}$ & $\begin{array}{l}\text { [4] Si mala foemina tibi } \\
\text { dat consilium, quod illam } \\
\text { magis ames quam Deum, } \\
\text { sanctus Spiritus tibi dat } \\
\text { consilium, quod magis } \\
\text { ames Deum quam omnia } \\
\text { alia; et si tu, fili, credis con- } \\
\text { silio peruersae foeminae, } \\
\text { scias, quod mittis tuum cor- } \\
\text { pus in captiuitatem in infer- } \\
\text { nalem carcerem, de quo } \\
\text { nullo tempore exibis. }\end{array}$ \\
\hline
\end{tabular}




\section{In+ablativo / inter+acusativo / ablativo sin preposición}

\begin{tabular}{|c|c|c|}
\hline VII & VII & VII \\
\hline $\begin{array}{l}\text { [5] Quando uidebis, fili, } \\
\text { mulierem aliquam cum } \\
\text { paupertatis amictu, cuius } \\
\text { aspectus denotet honesta- } \\
\text { tem, et illa portet in brac- } \\
\text { chio suo suum pulchrum } \\
\text { puerum egene indutum... }\end{array}$ & $\begin{array}{l}\text { [5] Quando, fili, uidebis } \\
\text { aliquam pulchram I mulie- } \\
\text { rem paupere indutam, et } \\
\text { suus aspectus significabit } \\
\text { tibi honestatem, et illa por- } \\
\text { tat suum pulchrum filium } \\
\text { inter sua bracchia inditum } \\
\text { paupere }\end{array}$ & $\begin{array}{l}\text { [5] Fili, quando uidebis } \\
\text { aliquam pulchram iuuenem } \\
\text { foeminam paupere uesti- } \\
\text { tam, et illius aspectus tibi } \\
\text { significat honestatem, et } \\
\text { illa portat suum pulchrum } \\
\text { filium suis bracchiis pau- } \\
\text { pere uestitum }\end{array}$ \\
\hline
\end{tabular}

\section{1. (Ablativo) / Genitivo / Ablativo}

\begin{tabular}{|c|c|c|}
\hline VIII & VIII & VIII \\
\hline $\begin{array}{l}\text { [16] Oportet, fili, ut mo- } \\
\text { riaris, uelis nolis. Ergo, } \\
\text { postquam mori te oportet, } \\
\text { placeat tibi mori in honore } \\
\text { illius domini, qui te ex } \\
\text { nihilo procreauit, ac tibi } \\
\text { quicquid habes elargitur; } \\
\text { qui etiam potest ignem per- } \\
\text { petuum tibi dare, et qui pa- } \\
\text { ratus est tibi dare gloriam } \\
\text { sempiternam, et qui tua uo- } \\
\text { luit dilectione mori. }\end{array}$ & $\begin{array}{l}\text { [16] Mori te oportet, fili, } \\
\text { uelis aut non. Ergo, post- } \\
\text { quam mori te oportet, opta } \\
\text { seu desidera mori amore } \\
\text { honorandi illum dominum, } \\
\text { qui te creauit, et qui tibi dat } \\
\text { omne, quod habes, et qui } \\
\text { potest tibi dare ignem aeui- } \\
\text { ternum, et qui tibi uult dare } \\
\text { gloriam, quae caret fine, et } \\
\text { qui amore tui uoluit pati et } \\
\text { mori. }\end{array}$ & $\begin{array}{l}\text { [16] Conuenit te mori, } \\
\text { fili, siue uelis siue nolis. } \\
\text { Igitur postquam debes } \\
\text { mori, uelis mori ad hono- } \\
\text { randum illum dominum, } \\
\text { qui te creauit, et qui tibi de- } \\
\text { dit omne, quod habes, et } \\
\text { qui tibi potest dare perdu- } \\
\text { rabilem ignem, et qui tibi } \\
\text { uult dare gloriam, quae non } \\
\text { habet finem, et qui ex tuo } \\
\text { amore uoluit mori. }\end{array}$ \\
\hline
\end{tabular}

\section{Genitivo / dativo}

\begin{tabular}{|l|l|r|}
\hline \multicolumn{1}{|c|}{ IIII } & \multicolumn{1}{|c|}{ IIII } & \multicolumn{1}{c|}{ IIII } \\
$\begin{array}{l}\text { [9] [...] quia homo est } \\
\text { Altissimo inoboediens per } \\
\text { peccatum, et Deus est ho- } \\
\text { mini inimicus, quando pec- } \\
\text { cat... }\end{array}$ & $\begin{array}{l}\text { [9] [...] quia per pecca- } \\
\text { Altissimo et Deus est ini- } \\
\text { micus homini, quando } \\
\text { committit peccatum... }\end{array}$ & $\begin{array}{l}\text { [9] [...] quia per pecca- } \\
\text { tum est homo inoboediens } \\
\text { Altissimo et Deus est ini- } \\
\text { micus hominis, quando } \\
\text { homo facit peccatum... }\end{array}$ \\
\hline
\end{tabular}




\section{Partitivo: Ex+ablativo / Genitivo / De+ablativo}

\begin{tabular}{|c|c|c|}
\hline$X$ & $X$ & $X$ \\
\hline $\begin{array}{l}\text { [5] [...] Et cum Filius Dei } \\
\text { ab eis recessisset, uenit be- } \\
\text { atus Thomas, qui erat unus } \\
\text { ex duodecim apostolis, qui } \\
\text { dixerunt ei Iesum Christum } \\
\text { resurrexisse. }\end{array}$ & $\begin{array}{l}\quad[5][\ldots] \text { Et ideo, quando } \\
\text { Iesus Christus discessit ab } \\
\text { eis, uenit sanctus Thomas, } \\
\text { qui erat unus apostolorum, } \\
\text { et dixerunt ei, quod Iesus } \\
\text { Christus resurrexerat. }\end{array}$ & $\begin{array}{l}\text { [5] [...] Et ideo quando } \\
\text { Iesus Christus ab eis dis- } \\
\text { cesserat, uenit sanctus Tho- } \\
\text { mas, qui erat unus de apos- } \\
\text { tolis, ad quem dixerunt, } \\
\text { quod Iesus Christus resu- } \\
\text { rrexisset. }\end{array}$ \\
\hline
\end{tabular}


